WORKING PAPER · NO. 2020-29

\title{
How Does Kompromat Affect Politics? A Model of Transparency Regimes
}

Monika Nalepa and Konstantin Sonin

JULY 2020 


\title{
How Does Kompromat Affect Politics? A Model of Transparency Regimes*
}

\author{
Monika Nalepa and Konstantin Sonin \\ University of Chicago
}

July 17, 2020

\begin{abstract}
Why are transparency regimes so rare? When some politicians have something to conceal, why would their opponents not press for transparency? To analyze transitional justice, we build a model that explains why uncompromised politicians might avoid a transparency regime, which could signal to the voters that they are clean. We model the interaction between an incumbent, an opposition leader, a strategic blackmailer, and voters who know that the opposition politician may be compromised. The incumbent can implement a transparency regime, which would force out a compromised opponent and thus make blackmail impossible. We show that, instead, she might strategically opt for no transparency that keeps all skeletons of the ancien régime in the closet, as it is easier to defeat a potentially compromised opponent. We corroborate our results using original data from the Global Transitional Justice Dataset combined with data on elections, incumbency, and successor autocrat status in post-communist Europe.
\end{abstract}

Keywords: transitional justice, transparency regime, blackmail, signaling.

JEL Codes: P26, D82.

${ }^{*}$ The authors are grateful for comments to the participants of the Formal Models and Comparative Politics workshop at Berkeley and the participants of the Political Economy lunch at the Harris School of Public Policy at The University of Chicago. 


\section{Introduction}

New democracies do not emerge in a vacuum. Legacies of former authoritarian states persist in the new polity in the form of unsettled scores of human rights abuses, former security agency staff members, and former secret police archives listing collaborators of the authoritarian security apparatus. The combined set of mechanisms designed to deal with these legacies is referred to as transitional justice (Elster, 2004; Aguilar, 2002; Aguilar, Balcells and Cebolla-Boado, 2011). Some of these mechanisms involve holding those responsible for human rights violations accountable for what they did in the past through criminal trials (Sikkink, 2011). Others simply rely on firing the administrative staff of the former state and security apparatus through post-authoritarian purges (Binningsbo et al., 2012).

A number of classical contributors to the literature on democratization and regime transitions in general have expressed skepticism about policies punishing functionaries of the ancien régime for human rights abuses committed in the past. Snyder and Vinjamuri (2004) argue that "the prosecution of perpetrators of atrocities according to universal standards risks causing more atrocities than it would prevent, because it pays insufficient attention to political realities." Holmes (1994) calls some forms of transitional justice "witch hunts." Cepl (1992) refers to such acts as "ritual sacrifices." Even Huntington (1993) maintains that sometimes "amnesty ... is necessary to establish a new democracy on a solid basis." Implicit in this classic literature is an understanding of transitional justice as a punitive process. Born out of this understanding is the use of the term "retroactive justice" as synonymous with transitional justice (Rev, 2005).

Crucially, not all forms of authoritarian dominance are as transparent as repression (Tyson, 2016). In many instances, the very acts that sustained the authoritarian regime were secret collaboration (Blaydes, 2010), cooptation (Magaloni, 2006), and sabotage (Dragu and Przeworski, 2019). Hence, another important way of dealing with the past is through the disclosure of such actions and the revelation of the identities of collaborators, spies, and saboteurs. This second class of transitional justice mechanisms - transparency regimes, or the revealing of who among persons holding public office collaborated with the secret police to the detriment of the anti-authoritarian opposition - is often left out of classical critiques. When Huntington says that "even if a moral and legal argument could be made for prosecution, this would fall before the normative imperative of 


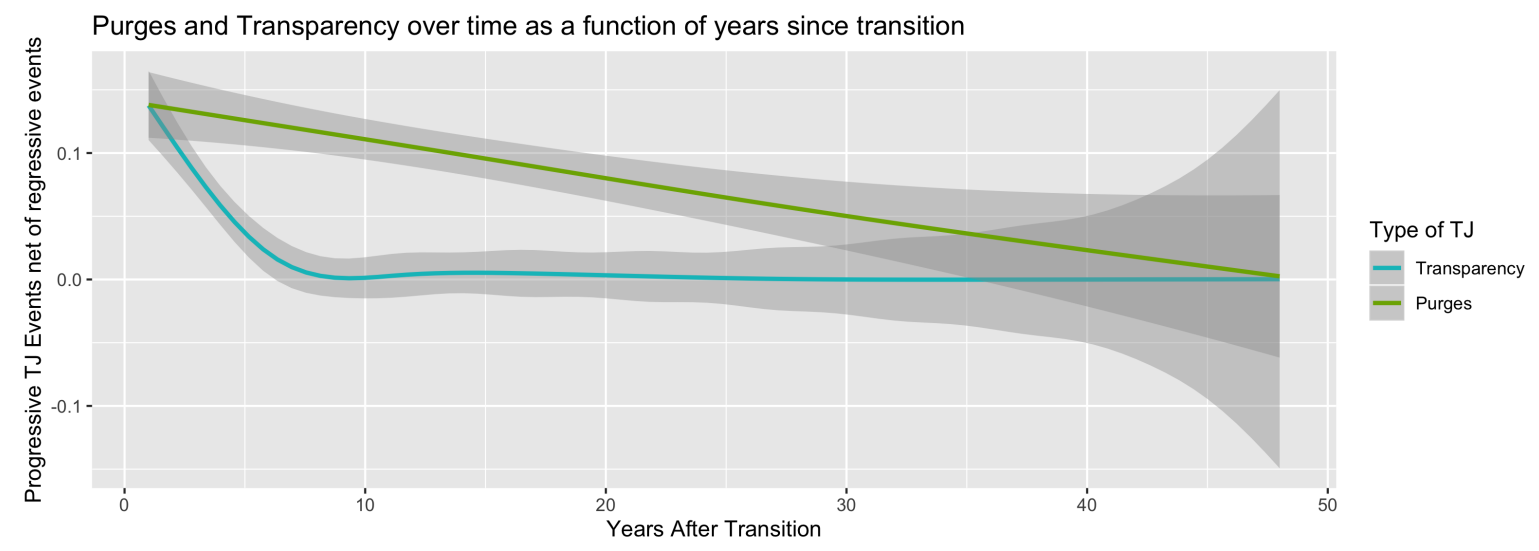

Figure 1: Purges and Lustration as a function of years lapsed since transition in 81 countries based on GTJD. Consistently with Bates, Cinar and Nalepa (2020), purges and lustration are measured as the number of positive events net of negative events per year.

creating a stable democracy," he implicitly assumes that transitional justice cannot be democracyenhancing. One of the first things we do in this paper is show that transparency regimes improve the quality of representation by bringing policy proposals closer to the preferences of the median voter than non-transparency regimes would.

However, while transparency regimes are better for democracy than a lack of transparency would be, this alone does not imply that they will be universally implemented. Indeed, a trend graph contrasting the adoption of transparency regimes (i.e., lustrations and truth commissions) with purges of state agencies of authoritarian agents and bureaucrats reveals that disclosing the truth about secret collaboration is much less frequent than firing and punishing its overt collaborators. Figure 1 is based on the Global Transitional Justice Dataset. Purges - the firing of known collaborators - is in green and transparency regimes are in blue. ${ }^{1}$ This figure makes clear that transparency regimes trail behind purges, suggesting that politicians in post-authoritarian states are considerably more reluctant to implement measures disclosing secret collaboration with the authoritarian regime.

Of course, transparency might be dangerous for elected officials: when kompromat is revealed, the politician might be removed from office. In 2003, Lithuanian President Rolandas Paksas accepted an almost half a million dollar donation to his campaign from a foreign national. After

\footnotetext{
${ }^{1}$ The specific measure reflected in the trends is based on "net TJ severity" developed by Bates, Cinar and Nalepa (2020) and defined annually as the total number of positive events (that is, moving transitional justice forward) net of negative events (that is, moving transitional justice backward).
} 
state security uncovered that the donor, Yuri Borisov, had ties to the Russian mafia, Paksas faced an impeachment proceeding in the Lithuanian legislature. In early 2004, he was found guilty and not only removed from the presidency, but also banned for life from running for office (Clark and Verseckaite, 2005). This example illustrates that a compromised politician may have strong reasons to delay or block the implementation of a transparency regime. Yet why would uncompromised politicians favor delays? If their opponents are suspect of secret collaboration with former regimes, implementing transparency should be a sound strategy for staying in power.

The theory we propose here presents a strategic reason why politicians refrain from implementing transparency regimes. We show, as a counterpoint to the anecdote above, that incumbents might refuse to implement transparency even when they themselves have no skeletons in the closet. Assuming the incumbent in power is clean herself allows us to tackle the hardest case in this argument: even where transparency, on the surface, should benefit the incumbent most, we demonstrate that for a wide range of circumstances it is still not implemented. ${ }^{2}$ Incumbents suppress transparency, reducing the quality of representation in new democracies, because they are more likely to win elections when voters suspect that challengers can be blackmailed with kompromat concerning the opposition's past collaboration. Thus, our model shows both that transitional justice - in the form of transparency regimes - is good for democracy, and explains why it is so rare.

We model strategic interaction between an incumbent, a (potentially compromised) challenger, an agent of the ancien régime's security apparatus, "the blackmailer", and voters who care primarily about policy yet dislike politicians who are proven to be collaborators. The key feature of the model is that the member of the ancien régime's security apparatus has private information about whether a member of the opposition and challenger to the incumbent has done something embarrassingsuch as collaborated with the security police prior to the transition - in the past. Hence, this is a model of the consequences of hidden influence: kompromat (Hubert and Little, 2019). In Section 2, we discuss the modeling challenges that any researcher of blackmail has to deal with.

In a political competition, anything that reduces the electability of a challenger should be brought to light by the incumbent. Thus, the delay or complete absence of transparency when suc-

\footnotetext{
${ }^{2}$ Yet, to apply our model to a broad range of cases, we later relax the assumption that the incumbent cannot be compromised. In Proposition 5, we show that even if the incumbent is suspected of being compromised, and implementing transparency would signal that she has no skeletons in her closet, she might still prefer to avoid transparency.
} 
cessor autocrats (or other parties who have no skeletons in the closet) are in power is puzzling. Our theory offers a mechanism explaining the incumbent's reluctance towards transparency. Proposition 1 describes the equilibrium conditions under which the incumbent refrains from transparency. Intuitively, the incumbent's desire to avoid transparency increases with the distance between her policy preferences and the median voter's (Proposition 2). It also increases with the probability that the opposition leader is compromised with the probability that his policy preferences are extreme (Proposition 3).

Our results survive a number of robustness checks. In Section 4, we consider the probabilistic version of the model, re-order the ideal point of the blackmailer vis a vis that of the incumbent, and analyze the case when the incumbent herself might be compromised. Our main insights are stable across all these extensions: the blackmailer releases kompromat if and only if the compromised leader does not, to some extent, respond to his demands. Anticipating this, the incumbent prefers to run against an opponent who is tainted by suspicion rather than against an opponent who is free of kompromat with certainty.

Thus far, to explain delays in the implementation of transparency regimes, scholars have focused on structural explanations. ${ }^{3}$ These explanations included a focus on the severity of the preceding authoritarian regime (Olsen, Payne and Reiter, 2010), but also on the fact that in the aftermath of transition to democracy, successor authoritarian parties are often elected into office (GrzymalaBusse, 2002). ${ }^{4}$ Some recent contributions to the dynamics of transitional justice have focused on the leverage that outgoing elites have when negotiating the transition to democracy (Przeworski, 1991; Albertus and Menaldo, 2014). In recent influential work, Helmke, Jeong and Ozturk (2019) have demonstrated that prosecuting former executives is more effectively explained by electoral competition than by rule of law considerations.

The above works suggest that transitional justice is avoided by post-authoritarian incumbents when it hurts them. Such explanations may account for why authoritarian successor parties avoid criminal trials or purges of known collaborators of the former authoritarian state. Still, they are

\footnotetext{
${ }^{3}$ In addition, scholars of international relations have also formulated arguments according to which the involvement of the international community (Prorok, 2017; Loyle and Appel, 2017; Krcmaric, 2018) can induce transitional justice delays, particularly in instances where relying on international resources can economically benefit the country in question (Simmons and Hopkins, 2005).

${ }^{4}$ For instance, Grzymala-Busse (2002) argues that in Post-Communist Europe, former authoritarian elites' "usable" skills allow them to form successful successor authoritarian parties.
} 
unable to account for delays in the implementation of transparency regimes, when the "dirt" to be revealed would not hurt the incumbent at all, but rather would expose skeletons only in the former opposition's closet (Nalepa, 2010). Information about collaboration with the secret police of the ancien régime does not significantly hurt former authoritarian elites: it is commonly known that members of authoritarian parties collaborated with the secret police, which in turn worked for the autocrats. Collaboration was expected of them and known. In contrast, a revelation that former dissidents worked with the secret police and denounced fellow members of the opposition can be truly damaging for these dissidents-turned-politicians' careers. $^{5}$

Formal models of transitional justice generally fall into two categories. The first set of formal models of transitional justice focuses on how autocrats discipline their agents of repression. The dilemma faced by autocrats is highlighted by Powell (2014): "a weak military can leave them vulnerable to [...] civil war, while a strong military [...] to a coup d'état." Paine (2019) has recently argued that the same reasoning can be applied to internal security forces. Authoritarian leaders have two choices: first, they can maintain weak or fragmented security forces, thus guarding against a coup d'état but risking resistance from below. Second, they can invest in strong state security at the risk of empowering a strong competitor.

Dragu and Lupu (2018) use a coordination game with incomplete information to show that, paradoxically, repression is most likely to hinge on expectations and become a coordination game when authoritarian leaders need it most (when dissent against them is at its highest). While in Dragu and Lupu (2018), the autocrat's dilemma is limited to the authoritarian regime, Tyson (2016) extends the consequences of the autocrat's actions and his agents of repression beyond the authoritarian regime, allowing for transitional justice. If the stability of the authoritarian regime is uncertain, the autocrat must compensate his agents of repression to offset their potential of being punished should the regime collapse. Tyson's model uses the prospect of transitional justice to model repressive agents' incentives, and his theory assumes that the identity of these agents is known. This need not be the case, however. Moreover, the availability of information on who in

\footnotetext{
${ }^{5}$ The case of Lech Walesa, the Solidarity trade union leader in 1980s and the president of post-communist Poland from 1990 to 1995 who was revealed to have worked for the secret political police is an illustration. According to the files from secret police archives analyzed by two historians, Walesa was recruited by the secret police of communist Poland when he was an electrician at the Gdansk shipyard, which was long before becoming Solidarity leader. He severed the relationship with his agents and ceased providing them with any information six years before the famous strike standoff in the shipyard. Yet were Walesa still in the office in 2008, when the revelations first surfaced, his career would have suffered even more dramatically than his legacy did (Cenckiewicz and Gontarczyk, 2008).
} 
the past was or was not a secret collaborator of the ancien régime depends on the transparency regime, which is itself a subject of strategic choice in our model.

The second category of papers studies the extent to which different types of transitional justice enhance representation. For instance, Ang and Nalepa (2019) note that secret legacies of the ancien régime can become a dangerous instrument in the hands of a blackmailing former security officer who may use this kompromat to influence policy choices of the newly elected democratic politician. Our model expands the set of strategic players to include voters, who update their beliefs using not only the release of kompromat, but also upon observing the policy choice of the elected official. Crucially, policy concessions are potentially indicative of the politician being compromised. In other words, we assume that everyone, including the voters, is a rational, utility-maximizing actor.

Hubert and Little (2019) draw on both strands of transitional justice literature and conceptualize the collection of embarrassing information by authoritarian principals on their agents as a way of disciplining them. These authors use a cheap talk game to account for the possibility of kompromat being leaked. Our model departs from Hubert and Little (2019) in that it focuses on consequences rather than origins of kompromat. Our blackmailer cannot generate kompromat but he can use it to force compromised politicians into making concessions.

None of the formal models of transitional justice cited combine the theoretical implications with empirical testing. Our paper, however, engages in such empirical corroboration. For empirical corroboration, we choose a medium- $n$ analysis. Focusing on post-communist electoral terms from 1990 though 2018, we show that in circumstances matching the assumptions of our model the volume of transparency regimes is indeed lower than usual (with "usual" defined as circumstances not matching the circumstances of our model). The unit of analysis of the empirical section is such that our entire universe of cases spans 14 electoral terms. We believe that such a meso-level analysis is the best of both worlds: it allows us to precisely operationalize most of our parameters of interest without cherry picking cases that support our insights. For the dependent variable, we rely on our original Global Transitional Justice Dataset. This dataset codes at the most granular level transparency regimes around the world by disaggregating them at the event level. This allows us to distinguish between transparency regimes that are severe and the ones that are relatively mild. Independent variables are operationalized with several variables from the Chapel Hill Expert Survey. A large- $n$ test is not feasible in the case of a model with such a high level of intervening 
variables. Forcing such a test would call for dubious operationalization criteria and would be, we believe, far less convincing.

The rest of the paper is organized as follows. Section 2 briefly discusses modelling blackmail, the core element of our theory. Section 3 presents and analyzes our baseline model, while Section 4 considers extensions. In Section 5, we illustrate the comparative statics of our model with the medium- $n$ analysis described above. Section 6 concludes.

\section{Modeling Blackmail}

Our theoretical model draws on two strands of literature. First, it is a model of transitional justice in that it deals with implications of behavior under an ancien régime for the quality of political representation under a new democratic regime. Second, it is a model of blackmail, that is, of hidden influence through the threat of public disclosure of information that voters consider disqualifying for holding public office. This section situates our model in the context of the existing models on the subject.

In political science, the problem of blackmail with kompromat and its potential to hurt a new polity's democratization prospects has been appreciated but remains poorly understood. There exists a consensus among scholars that the source of kompromat is the work of former secret police agents. ${ }^{6}$ It is also commonly believed that lustration is capable of putting a stop to the use of kompromat, ${ }^{7}$ though how exactly this happens has eluded social scientists. Hence Karklins (2005) believes that since "kompromat is most often used by corrupt individuals and networks to protect themselves against rivals, this knowledge of guilt is mutual and therefore acts mostly as a deterrent to preserve the status quo," implying that the only protection against kompromat it counter-kompromat (defined as an "even greater skeleton in the closet", Karklins, 2005, page 36). Alternatively, an institutional solution to the problem of kompromat might be necessary: Karklins

\footnotetext{
${ }^{6}$ See for example (Los, 2003, page 160): "Blackmail is also related to the secret information amassed in the archives of the former regime....this knowledge constituted the very foundation of the communist power. Under the new conditions it did not lose its political value as it could be easily translated into secret power over certain groups, political organizations and individual politicians. It could also be exchanged for money and influence."

${ }^{7} \operatorname{Los}$ (2003, page 161) writes: "Especially in the countries where no lustration procedures existed during the new states formative years, numerous secret police collaborators - whose concealed past made them vulnerable to blackmail and manipulation - were deliberately catapulted to positions of influence in politics, diplomacy, business, justice system and so forth."
} 
(2002) writes that corruption resulting from kompromat "tends to be self-perpetuating. Fear of exposure of previous corrupt dealings leads to additional corrupt acts, through both blackmail and bribery, to prevent investigations. Unless there is a decisive and institutionally based break in the spiral of corruption, the trend will only grow" (Karklins, 2002, page 30). Offe (1992)'s conclusions call for even more urgency: "In all post-communist regimes, it is evident that ...a general amnesty ... would also allow people to move into leadership positions whose involvement in the former regime makes them liable to blackmail through the threat of exposure. Something must be done" (Offe, 1992, page 195). And yet, as Figure 1 clearly indicates, institutional solutions have been few and far between.

The formal study of blackmail has long been the domain of scholars of law and economics (Coase, 1988; Posner, 1993; Shavell, 1993) and international relations (Schelling, 1960; Ellsberg, 1968). Contrary to conventional wisdom, blackmail is an elusive concept to describe in a model of public policy. There are two conceptual challenges: the first is making the public uncertain as to whether the actions of a possibly compromised politician are the result of genuine policy preferences or a response to blackmail; the second is creating an incentive for the blackmailer to release kompromat when the compromised official does not yield to his demands.

For kompromat to work, voters must react to its release: either by censoring the politician or removing him from office. Otherwise, a compromised politician would simply ignore the presence of kompromat. Thus, when the possibly compromised politician chooses a policy, the voters should not be certain if the policy is a result of yielding to blackmail or it is attributable to the politician's genuine policy preferences. If the voters knew with certainty that a policy was the result of blackmail, they would instantaneously punish the politician. It follows that any model of kompromat requires at least four cross-cutting types of the politician: First, naturally, there must be compromised and uncompromised politicians. A second requirement is uncertainty about the uncompromised politician's true preferences. Were these preferences uniquely associated with a some policy, any deviation from this policy would expose the politician as compromised. Consequently, the kompromat in possession of the blackmailer would be useless. For the blackmailer to have any leverage over the compromised politician, he must be able to choose a policy preferred by some uncompromised politician. This politician then faces a choice: he can succumb to the blackmailer or choose a different policy, be recognized as compromised, and be immediately removed from office. 


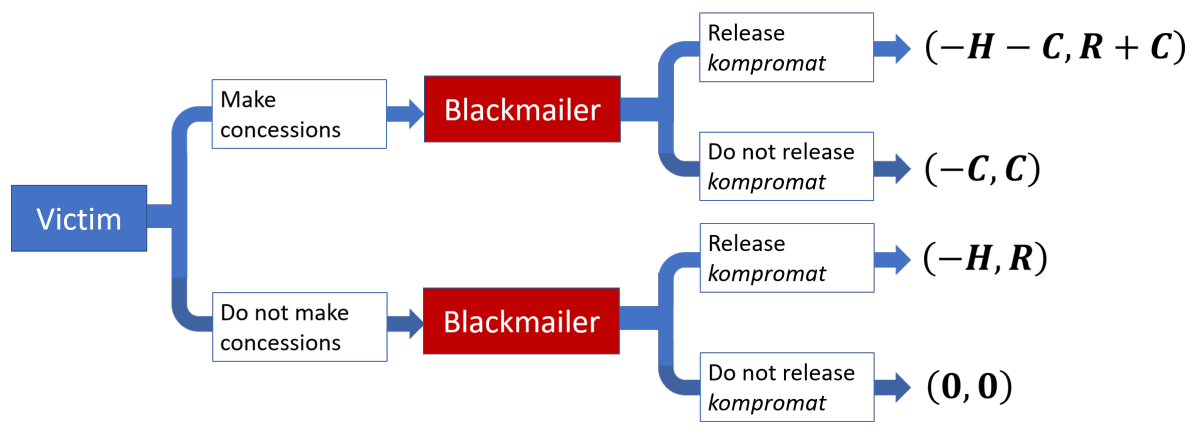

Figure 2: The "blackmail paradox": No matter how costly releasing kompromat is to the victim, $H>0$, and for every value of concessions that the victim could make to satisfy the blackmailer, $C>0$, in the unique subgame perfect Nash equilibrium, the victim does not concede regardless of whether the blackmailer enjoys releasing the kompromat $(R>0)$, or pays a cost $(R<0)$ to do so.

The second challenge is easiest to illustrate with a simple sequential game, which is the depicted in Figure 2. Here, first the victim chooses whether to make a concession; next the blackmailer decides whether to release kompromat. It can be easily seen that there is no subgame-perfect Nash equilibrium (SPNE) in which the victim concedes. Assume that if the victim concedes, he pays $C>$ to the blackmailer. If the blackmailer releases kompromat, the victim suffers the disutility of $-H$, where $H>0$, and the blackmailer receives the payoff of $R$. If the blackmailer suffers disutility as a result of releasing kompromat, $R<0$, then (Do not make concessions, Do not release kompromat) is a unique SPNE. If the blackmailer receives an additional payoff from releasing the kompromat, $R>0$, then (Do not make concessions, Release kompromat) is a unique SPNE. In either case and for any $H$ and $C$, the victim never concedes in equilibrium.

Thomas Schelling (Schelling, 1960) outlines the fundamental mechanism underlying this paradox for the one-shot case when $R<0$. Following the victim's move not to make concessions, fulfilling the threat is not incentive compatible. For $R>0$, no concessions are made in the first place because the blackmailer releases kompromat regardless of the victim's action. Addressing this issue, Shavell and Spier (2002) demonstrate that if carrying out a threat is costly for the blackmailer $(R<0)$, then even in an infinite-horizon setting, it is not possible to extract a concession from the victim. Schwarz and Sonin (2008) provide a mechanism for the blackmailer to extract the total surplus from the victim, but this mechanism requires randomized punishments along the equilibrium path, and leans heavily on the infinite interaction horizon.

In our game, despite its one-shot nature, it is subgame-perfect for the blackmailer to release 
the kompromat when the concession is not made. The reason is that after kompromat is released and the elected official is removed from office, his replacement who emerges following the elections may have genuine policy preferences that are favorable to the blackmailer. (As explained above, for blackmail to have any effect on policy, there must be a possibility of an uncompromised politician with such preferences.) This possibility motivates the blackmailer to release kompromat when presented with a choice between a compromised politician who will not yield and new elections. Thus, our model resolves the "blackmail paradox": the blackmailer does not release kompromat when the compromised official yields to his demands, but releases it if the official does not.

\section{The Model}

In our model, there is an incumbent who is currently in power but facing an election. Before the election, she has an opportunity to implement a transparency regime. Since our goal is to explain why even politicians who are not themselves compromised might shield from a transparency regime those who are, we can think of the incumbent as the successor autocrat. This part of her identity is relevant to the extent that she is not compromised by having worked for the secret police. As explained above, authoritarian elites collaborated with the regime openly, and no secrets regarding this collaboration that could compromise them further exist (Elster, 2012). In contrast, members of the opposition were constantly recruited (with varying success) to serve as secret police informers as the secret police attempted to gather information on dissident activities. ${ }^{8}$

\subsection{Formal Setup}

There are four strategic players with preferences over the one-dimensional policy space $\mathbb{R}$ : an incumbent, $I$, with ideal point $x_{I}$, an opposition challenger, $O$, with ideal point $x_{O}$, the voters represented by the median voter, $m$, with ideal point $x_{m}$, and a blackmailer, $B$, with ideal point $x_{B}$.

Politicians cannot commit to policy platforms: once in office, they do what is optimal for them. ${ }^{9}$

\footnotetext{
${ }^{8}$ Without any loss of generality, the successor autocrat could be a reformed communist party member. In this case, the ideal points of both a moderate- and extreme-type opposition challenger would be on the right side of the political spectrum.

${ }^{9}$ This assumption is not necessary; it is a straightforward exercise to extend the model allowing politicians to commit to policies in a one-dimensional policy space.
} 
The incumbent has policy preferences $U_{I}=-\left|x-x_{I}\right|$, and voters know her ideal policy $x_{I}>0$.

The opposition leader's preferences are $U_{O}=-\left|x-x_{O}\right|$. While the policy preferences of the incumbent are known, the precise preferences of the opposition challenger are not. We assume that the ideal policy of the challenger is either extreme (with ideal point $x_{O}^{E}$ ) or moderate (with ideal point $x_{O}^{M}$ ), with ideal point $x_{O}^{E}<x_{O}^{M}<0$. Neither voters nor the incumbent know with certainty the challenger's type. This uncertainty is captured by the parameter $\theta \in(0,1)$, where $P\left(x_{O}=x_{O}^{M}\right)=\theta$ and $P\left(x_{O}=x_{O}^{E}\right)=1-\theta$. We will focus on the most interesting case, when $x_{I}>\left|x_{O}^{M}\right|$; this is the case where the incumbent would lose elections to an opposition leader known with certainty to be of the moderate type.

There is also a second layer of uncertainty concerning the opposition leader: both the incumbent and the median voter know that the opposition leader might be compromised with embarrassing material collected against him by the former security apparatus, and have ex ante correct expectations about the probability $\mu$ that the challenger is compromised. The opposition leader himself knows his own type with certainty. We assume that regardless of the policy that he implements, the opposition leader prefers to stay in office.

Additionally, all players are aware of a blackmailer who, if the opposition leader is compromised, is in a position to publicly disclose the compromising information. The blackmailer's policy preferences are $U_{B}=-\left|x-x_{B}\right|$ with $x_{B}<x_{O}^{E}$.

Voters' preferences are represented by a median voter with the ideal point $x_{m}=0$ and the utility function $U_{I}=-|x|$. In addition to the policy preferences, voters suffer $\varepsilon$ if they retain a compromised opposition leader and $D$ if an uncompromised leader is removed. We assume $\varepsilon>0$ to be close to zero reflecting voters' preferences for an uncompromised leader, ceteris paribus; yet it is voters' policy preference that is of the first order. ${ }^{10}$ In contrast, the disutility from removing an innocent and duly elected leader, $D>0$, is substantial. ${ }^{11}$

In elections following the removal of the elected leader, the new opposition leader is drawn from the same ideological type distribution as previously. Consequently, he is moderate with probability

\footnotetext{
${ }^{10}$ In assuming that information about kompromat affects voters' welfare, we follow established political economy scholarship according to which voters are better off making electoral decisions when more information is available to them (Penn, 2016).

${ }^{11}$ We need this assumption for a simple reason: if there is no cost of removing innocent leaders, voters might want to keep removing them one settles on $x_{O}^{M}$, which is closer to $x_{m}$ then $x_{O}^{E}$.
} 
$\theta$ and extreme with probability $1-\theta \cdot{ }^{12}$

The timing of the game is as follows:

\section{Timing}

1. The incumbent chooses the regime: either transparent, in which all information is released, or non-transparent.

2. Elections take place; voters choose between the incumbent $(I)$ and the opposition leader $(O)$.

3. The politician $P \in\{I, O\}$ that wins chooses the policy $x_{P}^{*}$. The choice of the opposition leader might depend on whether or not he is compromised.

4. If the winner is the compromised opposition leader, the blackmailer decides whether to release kompromat.

5. Voters update their beliefs about the winner's type based on policy choice and kompromat publication and decide whether to remove him from office.

6. If the winner is ousted, new elections are held with the opposition leader drawn from the same (restricted to policy preferences) type distribution.

7. Pay-offs are received.

In our baseline model, we assume that there is no uncertainty about the incumbent's type. In Subsection 4.3, we relax this assumption and demonstrate that even if choosing transparency might send a credible signal about her being not compromised, the incumbent might prefer to choose non-transparency.

Our equilibrium concept is perfect (Bayesian) equilibrium (Myerson, 1990). In this equilibrium, voters form beliefs about the type of electoral winner on the basis of his policy choice and on whether kompromat has been released. Among perfect equilibria, we select the one that satisfies the intuitive criterion (Cho and Kreps, 1987). Essentially, the criterion allows to eliminate equilibria, which rely

\footnotetext{
${ }^{12}$ The results will not qualitatively change if we assume that the opposition leader in the new elections might be compromised as well. In fact, the equilibrium path in this new game is the same. However, assuming that new elections do not feature compromised challengers greatly simplifies the algebra. Barring this assumption, we would have a game featuring the possibility, albeit an increasingly slim one, of infinite recursion.
} 
on unnatural off-equilibrium-path beliefs (see Myerson, 1990, Chapter 5). In our model, it allows to eliminate equilibria that rely on voters' beliefs that force the uncompromised politicians to choose anything but their ideal points after the election.

\subsection{Analysis}

Players' strategy sets and beliefs in a unique Bayesian equilibrium, in which politicians play their dominant strategies whenever they have one, are characterized formally in the Appendix. Here, we convey the intuitive solution.

We proceed backwards, starting from the final stages of the game. Suppose, first, that the opposition leader has won. If kompromat is not released, the only information that the voters can use to update their beliefs is the elected leader's policy choice. The equilibrium selection criterion that we use requires players to use dominant strategies. Thus, if the opposition politician elected into office is not compromised, he chooses $x_{O}^{*}=x_{O}^{i}, i \in\{E, M\}$, his true ideal point.

However, if the elected opposition leader is compromised, he faces different incentives because the blackmailer can force him to take the extreme position. Let $p$ denote the probability that the voters attach to the possibility that the election winner is compromised. If kompromat is released, the voters know with certainty that the elected leader is compromised $(p=1)$. In this case, removal of the leader results in new elections with opposition candidates drawn from the same distribution, which is strictly preferred by the voters. If kompromat is not released but the elected politician has chosen any policy $x$, besides $x_{O}^{M}$ and $x_{O}^{E}$, the voters also know that he is compromised, because the non-compromised politician has no incentive to choose anything but his true preferences (which are either $x_{O}^{M}$ or $x_{O}^{E}$,).

For the blackmailer, it makes sense to release the kompromat against a leader who chooses the moderate position, $x_{O}^{M}$, as long as

$$
-E\left|x_{O}^{n e w}-x_{B}\right|=-(1-\theta)\left|x_{O}^{E}-x_{B}\right|-\theta\left|x_{O}^{M}-x_{B}\right|>-\left|x_{O}^{M}-x_{B}\right|
$$

where the left-hand side is the blackmailer's expected utility after the new election. Thus, if the blackmailer has kompromat to release against the opposition leader who has chosen the moderate position, he always does so. For the blackmailer, a lottery involving, with positive probability, a 
new opposition leader who is extreme is strictly preferable to the certainty of a moderate policy.

The compromised politician who is elected does not want to be exposed, so he will choose either $x_{O}^{M}$ or $x_{O}^{E}$. Since the blackmailer prefers the extreme policy among the two possible policy choices, the compromised politician chooses $x_{O}^{E}$. Otherwise, the blackmailer would release the kompromat. Summing up, since any policy choice but $x_{O}^{M}$ or $x_{O}^{E}$ reveals that the politician is compromised, in an equilibrium, the compromised politician chooses $x_{O}^{E}$ regardless of his true type and the blackmailer stays silent.

Thus, if the policy choice is $x_{O}^{M}$, the voters know that the elected leader is uncompromised $(p=0)$. If the policy choice is $x_{O}^{E}$, then, using Bayes' formula, we find that the voters believe that the elected leader is compromised with probability

$$
p=\frac{\mu}{\theta \mu+1-\theta}
$$

Given our assumptions about voters' payoffs, they would not remove the elected leader from office unless they are reasonably sure that he is compromised. ${ }^{13}$

Moving backwards, consider the choice of the median voter (with ideal point $x_{m}=0$ ) at the voting stage. Voting for the incumbent gives the median voter $-x_{I}$, while voting for the opposition leader results in $x_{O}^{M}$ with probability $\theta(1-\mu)$ and $x_{O}^{E}$ with probability $\theta \mu+(1-\theta)$. That is, the expected utility of voting for the opposition leader if there is no transparency is

$$
E u_{m}\left(x_{O}^{*} \mid N\right)=x_{O}^{M} \theta(1-\mu)+x_{O}^{E}(\theta \mu+(1-\theta)) .
$$

Thus, if there is no transparency the median voter votes for the opposition as long as

$$
u_{m}\left(x_{I}\right)=-x_{I}<x_{O}^{M} \theta(1-\mu)+x_{O}^{E}(\theta \mu+(1-\theta))=E u_{m}\left(x_{O}^{*} \mid N\right)
$$

Finally, when do we expect the incumbent leader to choose transparency? Empirically, this would entail publishing the contents of secret police archives or implementing a lustration law that would limit the release of materials only to persons running for or holding public office. In our

\footnotetext{
${ }^{13}$ When the probability that the elected leader is compromised is $p>0$, the expected payoff of removal is $-(1-$ $p) D+\theta x_{O}^{M}+(1-\theta) x_{O}^{E}$, while the expected payoff of keeping the leader is $x_{O}^{E}-p \varepsilon$. We assumed that $D$ is large enough to guarantee that $\frac{\mu}{\theta \mu+(1-\theta)}<\frac{D-\theta\left(x_{O}^{M}-x_{O}^{E}\right)}{D+\varepsilon}$, i.e., the elected official is not removed from office when $p=\frac{\mu}{\theta \mu+1-\theta}$.
} 


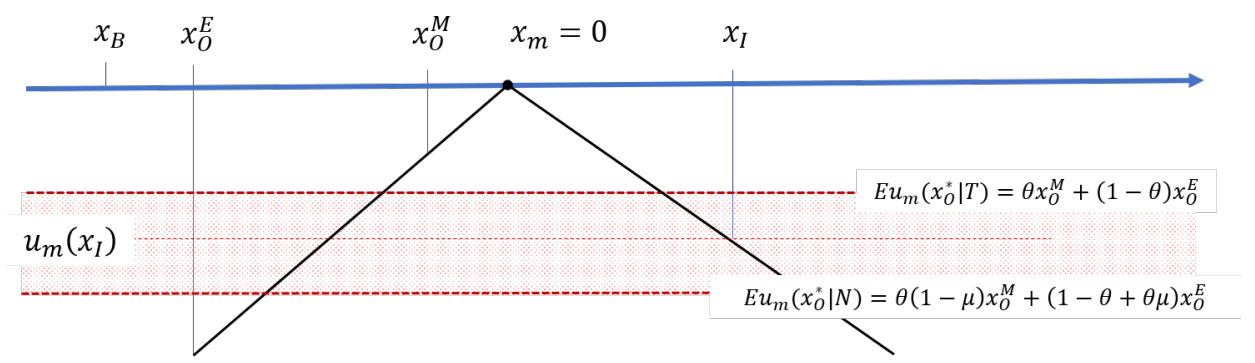

Figure 3: The median voter prefers the opposition leader under transparency, but if there is a chance that the opposition leader is compromised, prefers the incumbent. The expected median voter's utility of electing the opposition leader under no transparency decreases as $\mu$ rises (and the range of parameters under which the incumbent prefers non-transparency increases).

model, this means that the voter knows with certainty that the opposition leader running for office is uncompromised. In this case, the median voter's expected utility of voting for the opposition leader is

$$
E u_{m}\left(x_{O}^{*} \mid T\right)=x_{O}^{M} \theta+x_{O}^{E}(1-\theta)
$$

and the median votes for the opposition in the transparency regime as long as

$$
u_{m}\left(x_{I}\right)=-x_{I}<E u_{m}\left(x_{O}^{*} \mid T\right)=x_{O}^{M} \theta+x_{O}^{E}(1-\theta) .
$$

Now, if

$$
E u_{m}\left(x_{O}^{*} \mid N\right)<u_{m}\left(x_{I}\right)<E u_{m}\left(x_{O}^{*} \mid T\right)
$$

the incumbent chooses the non-transparency regime as she wins under non-transparency but loses with transparency. Given the incumbent's policy preferences, she prefers winning to losing because if she wins, she implements her ideal policy. Figure 3 illustrates this situation.

In Figure 3, the utility of the median voter from voting for the incumbent is given by the middle dashed red line. Conditions (1) are represented by the two red lines that correspond to the payoff of the median voter from voting for the opposition under non-transparency (bottom red) and transparency (top red) line.

The conditions described in expression (1) are equivalent to the pair of inequalities

$$
x_{I}<-x_{O}^{M} \theta(1-\mu)-x_{O}^{E}(\theta \mu+1-\theta) .
$$

and 


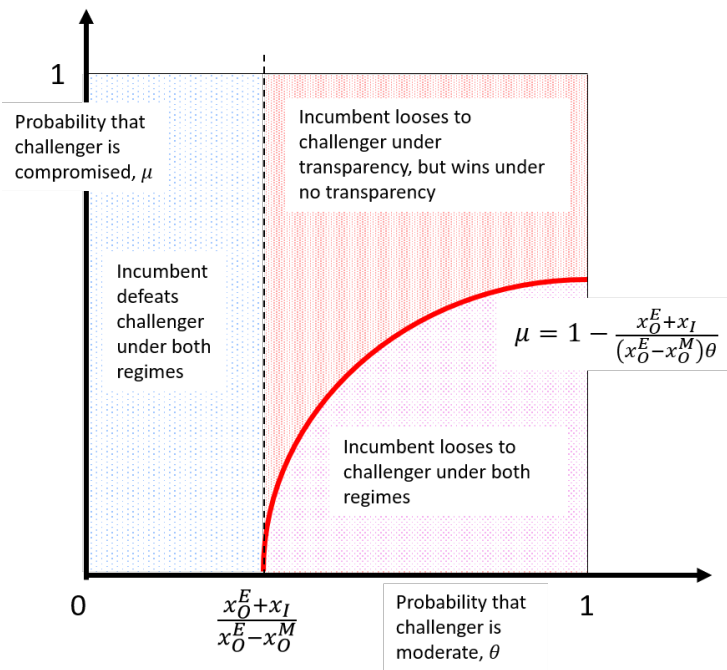

Figure 4: The election outcome as a function of the challenger type $(\theta, \mu)$.

$$
x_{I}>-x_{O}^{M} \theta-x_{O}^{E}(1-\theta)
$$

Start with condition (3). If the probability that the challenger is moderate, $\theta$ is low, $\theta \geq \frac{x_{O}^{E}+x_{I}}{x_{O}^{E}-x_{O}^{M}}$, then the incumbent wins under both transparency and non-transparency regimes. Now, fix any $\theta$ such that $\theta>\frac{x_{O}^{E}+x_{I}}{x_{O}^{E}-x_{O}^{M}}$. As $-x_{O}^{E}>x_{I}$ by assumption, there exists $\widetilde{\mu}=1-\frac{x_{O}^{E}+x_{I}}{\left(x_{O}^{E}-x_{O}^{M}\right) \theta}(\theta)>0$ such that for any $\mu \in[\widetilde{\mu}, 1]$, condition (2) is fulfilled. Thus for any pair of parameters $(\theta, \mu)$ such that $\mu \in[\widetilde{\mu}(\theta), 1]$, the incumbent will prefer no transparency. Proposition 1 formally summarizes the above analysis.

Proposition 1 There exists a threshold $\widetilde{\mu}, 0<\widetilde{\mu}<1$ for the probability that the opposition is compromised space such that for any pair of parameters $(\theta, \mu)$ where $\mu \in[\widetilde{\mu}(\theta), 1]$, there exists a unique equilibrium. In this equilibrium, the uncompromised opposition leader chooses his ideal point; the compromised opposition leader chooses the extreme left position $x_{O}^{E}$; voters vote for the incumbent and remove the elected opposition leader from power unless his policy choice is either $x_{O}^{M}$ or $x_{O}^{E}$; the blackmailer releases kompromat unless the compromised opposition leader chooses $x_{O}^{E}$; and the incumbent chooses not to implement a transparency regime.

On the equilibrium path that Proposition 1 describes, the incumbent does not implement transparency and voters choose her over the opposition leader. However, every other element of the equilibrium matters: voters prefer the incumbent, because their correctly foresee that the opposi- 


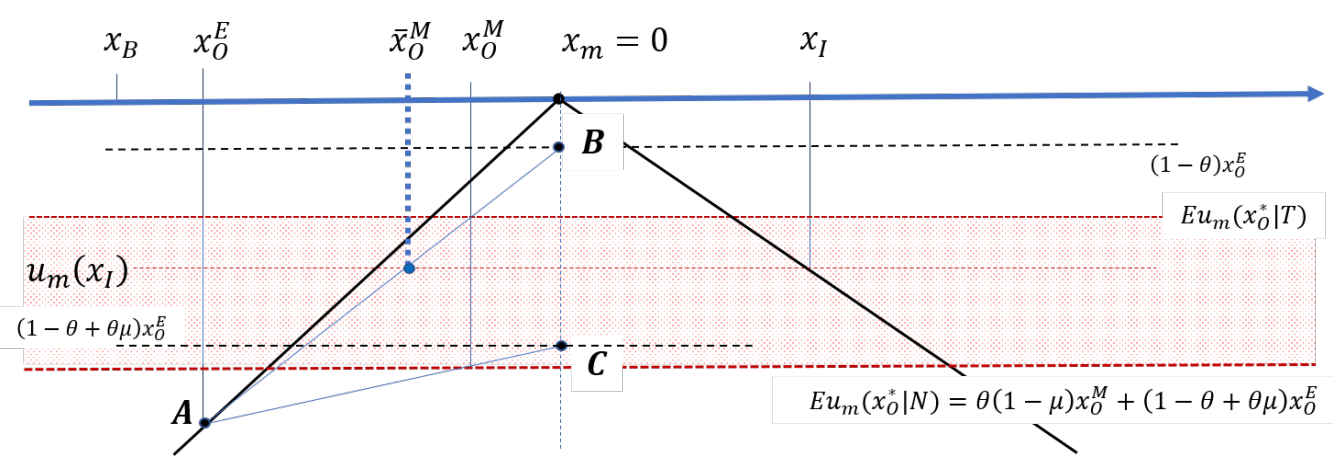

Figure 5: Comparative statics with respect to the ideal point of the moderate opposition leader, $x_{O}^{M}$. Under the transparency regime, the incumbent loses to all opposition challengers with moderate positions to the right of $\bar{x}_{O}^{M}$ (represented by the dotted blue line).

tion leader, once elected, is compromised with some probability, and, if compromised, is going to pander to the blackmailer. This, in turn, happens because the blackmailer's equilibrium behavior is to release kompromat unless the elected politician follows his demands. Finally, the blackmailer does this because of the beliefs that voters rationally form observing the politician's policy choice.

One immediate corollary of Proposition 1 is that a transparency regime, if implemented, would improve social welfare. Under transparency, the concern that the opposition leader running for office is compromised disappears. As a result, a moderate opposition leader would defeat the incumbent, increasing the voters' welfare. Without transparency, the outcome is inferior.

\subsection{Comparative Statics}

What happens when the probability that the politician is compromised increases? Does a more centrist incumbent have stronger incentives to implement a transparency regime? In this subsection, we explore the comparative statics of the model, which we later bring to data in Section 5 .

Figure 3 illustrated the simple comparative statics with respect to $\mu$, the probability that the opposition leader is compromised. There, an increase in $\mu$ led to a decrease in $E u_{m}\left(x_{O}^{*} \mid N\right)$. In Figure 3, an increase in $\mu$ shifted the bottom red line down: an increase in the probability that the compromised moderate opposition leader mimics the extreme type in order to avoid having kompromat exposed put more weight on $x_{O}^{E}$. In other words, a more susceptible to kompromat opposition leader increased the incumbent's advantage from non-transparency.

The next figure, Figure 5, addresses the question of how the location of the moderate opposition leader affects the choice of transparency regime. To see this, let $x_{O}^{M}$ vary between $x_{O}^{E}$ and $x_{m}=0$. 
The associated expected utility of voting for the opposition when there is transparency is represented by the line $\mathrm{AB}$. The line $\mathrm{AC}$ represents the median voter's utility for voting for the opposition (also as $x_{O}^{M}$ varies between $x_{O}^{E}$ and $x_{m}=0$ ) under the no transparency regime. Note that for any specific location of the moderate opposition leader, such as $x_{O}^{M}$ in Figure 5 , the lines $\mathrm{AB}$ and $\mathrm{AC}$ must intersect with $x_{O}^{M}$ at the lines representing the expected utility of voting for the opposition under transparency $\left(E U\left(x_{O}^{*} \mid T\right)=(1-\theta) x_{O}^{E}+\theta x_{O}^{M}\right)$ and no transparency $\left(E U\left(x_{O}^{*} \mid N\right)=\right.$ $\left.(\mu \theta+(1-\theta)) x_{O}^{E}+(1-\mu) \theta x_{O}^{M}\right)$, respectively. Consequently, the shaded red area describes the range of utilities of the median voter, in which the incumbent loses under transparency but wins without it. To the right of $\bar{x}_{O}^{M}$, where $\mathrm{AB}$ intersects the $u_{m}\left(x_{I}\right)=-x_{I}$ line, the incumbent loses under transparency, but wins when there is no transparency. Hence, the dotted blue line, marks the critical position of $x_{O}^{M}=\bar{x}_{O}^{M}$ to the right of which the incumbent will be best off stalling the implementation of the transparency regime.

The critical location of the moderate opposition (marked by the dotted blue line in Figure 5), at which the incumbent prefers non-transparency to transparency can be found analytically after setting $E u_{m}\left(x_{O}^{*} \mid N\right)=\theta(1-\mu) x_{O}^{M}+(1-\theta+\theta \mu) x_{O}^{E}$ equal to $-x_{I}$ and solving for $x_{O}^{M}$. After solving for this expression, we arrive at the following:

Proposition 2 For any fixed proportion of collaborators, $\mu$, and probability of the opposition leader being moderate, $\theta$, there exists a critical location of the moderate opposition leader $\bar{x}_{O}^{M}$ such that any $x_{O}^{M} \geq \bar{x}_{O}^{M}$ ensures that a transparency regime will never be implemented by the incumbent.

How does the location of the incumbent's ideal point affect her decision to implement a transparency regime? Figure 6 illustrates the logic behind the answer to this question, while Proposition 3 presents the results formally.

For the non-transparency regime, as $\theta$ changes from 0 to 1 , the median voter's payoff from voting for the opposition challenger, $E u_{m}\left(x_{O}^{*} \mid N\right)$, is represented by the red line between points A and B. In the case of transparency, as $\theta$ changes from 0 to 1 , the median voter's payoff from voting for the opposition challenger, $E u_{m}\left(x_{O}^{*} \mid T\right)$, is represented by the blue line running from point A to C. If in Figure 6, we fix some intermediate $\theta$, we can represent the median voter's payoff under the non-transparency regime with the red dashed line and under the transparency regime (that same intermediate $\theta$ ) with the blue dashed line. To determine which decision is more beneficial to the 


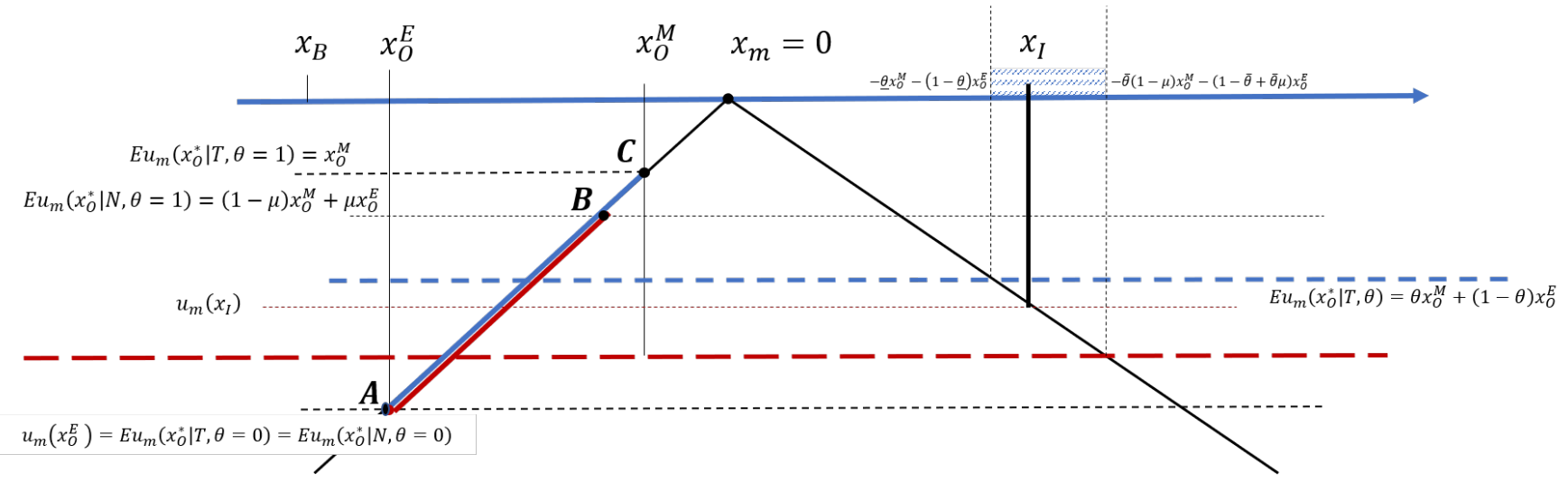

Figure 6: Transparency decisions by different types of incumbents: to the left of $-\underline{\theta} x_{O}^{M}-(1-\underline{\theta}) x_{O}^{E}$ the incumbent wins regardless of regime; to the right of $-\bar{\theta}(1-\mu) x_{O}^{M}-(1-\bar{\theta}) \mu x_{O}^{E}$ the incumbent loses regardless of regime.

incumbent, these payoffs are compared to $-x_{I}$, which corresponds to the median voter's utility from reelecting the incumbent. This allows us to distinguish a range of incumbent positions, where the incumbent will strictly prefer nontransparency to transparency.

Finally, we consider comparative static on $\theta$ and ask what is the lowest $\theta$ at which the incumbent benefits from non-transparency relative to transparency? We can calculate this $\underline{\theta}$ as follows.

Notice that for every $\theta, E u_{m}\left(x_{O}^{*} \mid T, \theta\right) \geq E u_{m}\left(x_{O}^{*} \mid N, \theta\right)$ and both $E u_{m}\left(x_{O}^{*} \mid T, \theta\right)$ and $E u_{m}\left(x_{O}^{*} \mid N, \theta\right)$ are increasing in $\theta$ because the median voter is better off when it is more likely that the moderate opposition wins. Hence, there exists $\underline{\theta}$ such that for any $\theta>\underline{\theta}$, the incumbent loses under transparency but wins under the non-transparency regime. This is the case because the median prefers the lottery between $x_{O}^{E}$ and $x_{O}^{M}$ with probabilities $(1-\underline{\theta})$ and $\underline{\theta}$, respectively, to the incumbent's ideal point. On the other hand, to the left of the $\underline{\theta}$, the median prefers the incumbent under both transparency and non-transparency regimes. The specific value of $\underline{\theta}$ is given by the solution to the expression

$$
-x_{I}=\theta x_{O}^{M}+(1-\theta) x_{O}^{E}
$$

We conclude that to the left of $\underline{\theta}$, the incumbent does not care for the nature of the regime, though to the immediate right of it she prefers non-transparency. In addition, there exists a $\bar{\theta}>\underline{\theta}$ such that for every $\theta>\bar{\theta}$, the incumbent loses under both transparency and non-transparency because the median prefers the lottery between $x_{O}^{M}$ and $x_{O}^{E}$ this time with weights that include $\mu$. 
$\bar{\theta}$ is the solution to

$$
-x_{I}=\theta(1-\mu) x_{O}^{M}+(1-\theta+\theta \mu) x_{O}^{E}
$$

The relationship between $\underline{\theta}$ and $\bar{\theta}$ is given by

$$
\bar{\theta}=\frac{\underline{\theta}}{1-\mu} .
$$

We notice immediately that the distance between $\underline{\theta}$ and $\bar{\theta}$ increases with $\mu$. We can use equations 4 and 5 to characterize the set of incumbents preferring non-transparency to transparency (the set representated by the three blue lines) as follows:

Proposition 3 Define the set $N T^{I} \equiv\left\{x_{I} \mid-\theta x_{O}^{M}-(1-\theta) x_{O}^{E} \leq x_{I} \leq-\theta(1-\mu) x_{O}^{M}-(1-\theta+\theta \mu) x_{O}^{E}\right\}$. Any incumbent with $x_{I} \in N T^{I}$ will prefer a non-transparency regime to a transparency regime. The size of the set $N T^{I}$ increases with the proportion of collaborators, $\mu$, the distance between the potential opposition challengers, and the probability, $\theta$, that the opposition challenger is in fact moderate.

An important caveat is in order here. Although it is tempting to translate the size of set $N T^{I}$ into a probability of implementing a transparency regime, we want to caution against this because incumbents with ideal points to the left of $-\theta x_{O}^{M}-(1-\theta) x_{O}^{E}$ win under both transparency and nontransparency regimes. In light of this, such incumbents have no particular incentives for maintaining transparency. However, incumbents with ideal points close to the median and hence characterized by $x_{I} \leq \theta-x_{O}^{M}-(1-\theta) x_{O}^{E}$ should be more prevalent (given that they emerge victorious in elections). At the same time, incumbents with ideal points greater than $-\theta(1-\mu) x_{O}^{M}-(1-\theta+\theta \mu) x_{O}^{E}$ will lose under both regimes and so do not have a preference for one over the other; such incumbents should be more rare. We conclude the baseline model by pointing out that the the effect of changes in $x_{I}$ is not monotonic, but is proportional to the distance between the opposition challengers.

\section{Uncertain Media and Compromised Incumbent}

In this section, we consider three extensions of our baseline model, which also serve as a robustness check. First, we consider an environment, in which the incumbent makes her choice about the 
transparency regime without knowing the ideal point of the median voter. Second, we show that our results do not require the assumption that the opposition leader, the target of blackmail, and the blackmailer are on the same side of the political spectrum. Finally, we introduce uncertainty about the kompromat status of the incumbent, giving her an incentive to use transparency to credibly signal her innocence. None of these robustness checks change our results.

\subsection{Uncertain Median}

In the baseline model, we assumed that the position of the median voter is known ex ante. In this section, we relax this assumption and define the ideal point of the median voter, $x_{m}$, by a random variable distributed uniformly over $\left[-\frac{1}{2 \delta}, \frac{1}{2 \delta}\right]$.

We start by calculating the probability that the opposition wins, given the parameters of the model, for both transparency and non-transparency regimes. In the model with uncertainty, the consequences of a transparency regime on the incumbent's re-election prospects are probabilistic. However, for a range of parameters, the incumbent still prefers non-transparency. This model can hence be interpreted as a robustness check on our main result that uncompromised incumbents protect compromised politicians by shielding them from transparency legislation that would expose skeletons in their closet.

Assume, as before, that $x_{B}<x_{O}^{E}<x_{O}^{M}<0<x_{I}$; assume also that $x_{m} \sim U\left[-\frac{1}{2 \delta}, \frac{1}{2 \delta}\right]$, which implies that for any given $x$, the probability that $x_{m}<x$ is given by $F(x)=\delta x+\frac{1}{2}$. We will assume that $\delta$ is large enough that $x_{O}^{M}<-\frac{1}{2 \delta}<0<\frac{1}{2 \delta}<x_{I}$.

Since the order of play is the same as before, the analysis of the median voter's and blackmailer's decisions will be the same as in the previous section. That is, the voters upon observing that kompromat has been released remove the elected leader; otherwise, they base their decision on the elected leader's policy choice. The blackmailer in turn, does not reveal kompromat if $x_{o}^{*}=x_{O}^{E}$, but reveals it whenever it is in his possession and $x_{O}^{*}=x_{O}^{M}$.

Recall, as before, that for the uncompromised politician, choosing anything but his ideal point is dominated by choosing his ideal point. Given this, in the equilibrium we construct, the compromised politician must select a policy from the set $\left\{x_{O}^{E}, x_{O}^{M}\right\}$. For any other values and beliefs, other policy choices can never be a part of an equilibrium that satisfies the intuitive criterion. Because his ideal

point would cost the moderate compromised politician his office, he chooses $x_{O}^{*}=x_{O}^{E}$. The extreme 
compromised opposition leader is free to chose his ideal point. Hence, all compromised politicians choose $x_{O}^{*}=x_{O}^{E}$ regardless of type.

Under a non-transparency regime, the median voter votes for the opposition if and only if

$$
x_{m}<\frac{x_{I}+x_{O}^{M} \theta(1-\mu)+x_{O}^{E}(1-\theta+\theta \mu)}{2} .
$$

Thus, the probability that the opposition wins under the non-transparency regime is

$$
P^{N T}=\frac{1}{2}+\frac{x_{I}+x_{O}^{M} \theta(1-\mu)+x_{O}^{E}(1-\theta+\theta \mu)}{2} \delta
$$

To find how the median votes under the transparency regime, we simply set $\mu=0$ in the above expression. The opposition wins if and only if

$$
x_{m}<\frac{x_{I}+x_{O}^{M} \theta+x_{O}^{E}(1-\theta)}{2},
$$

which implies a probability of defeating the incumbent under transparency of

$$
P^{T}=\frac{1}{2}+\frac{x_{I}+x_{O}^{M} \theta+x_{O}^{E}(1-\theta)}{2} \delta
$$

The probability of losing under transparency is higher: $P^{N T}>P^{T}$ whenever $\mu>0$.

If the incumbent wins, her utility is equal to zero. Hence, the remaining task is to calculate her expected utility conditional on losing under the transparency and non-transparency regimes:

$$
\begin{aligned}
E U_{I}\left(x_{O}^{*} \mid N T\right) & =-\left(x_{I}-x_{O}^{M}\right) \theta(1-\mu)-\left(x_{I}-x_{O}^{E}\right)(1-\theta+\theta \mu), \\
E U_{I}\left(x_{O}^{*} \mid T\right) & =-\left(x_{I}-x_{O}^{M}\right) \theta-\left(x_{I}-x_{O}^{E}\right)(1-\theta)
\end{aligned}
$$

(here, the expectation is taken with respect to the opposition politician's type). Clearly, the incumbent would prefer losing under transparency to losing under non-transparency as under the transparency regime, she is more likely to lose to the moderate opposition. 
Now, the expected utility of the incumbent under the non-transparency regime is

$$
\begin{aligned}
E U_{I}(N T) & =P^{N T} \times E U_{I}\left(x_{O}^{*} \mid N T\right) \\
& =\left(\frac{1}{2}+\delta \frac{x_{I}+x_{O}^{M} \theta(1-\mu)+x_{O}^{E}(1-\theta+\theta \mu)}{2}\right)\left(-\left(x_{I}-x_{O}^{M}\right) \theta(1-\mu)-\left(x_{I}-x_{O}^{E}\right)(1-\theta+\theta \mu)\right) .
\end{aligned}
$$

and under the transparency regime is

$$
\begin{aligned}
E U_{I}(T) & =P^{T} \times E U_{I}\left(x_{O}^{*} \mid T\right) \\
& =\left(\frac{1}{2}+\delta \frac{x_{I}+x_{O}^{M} \theta+x_{O}^{E}(1-\theta)}{2}\right)\left(-\left(x_{I}-x_{O}^{M}\right) \theta-\left(x_{I}-x_{O}^{E}\right)(1-\theta)\right) .
\end{aligned}
$$

When does the incumbent choose transparency? There is a trade-off because while the probability of winning is higher under non-transparency, the incumbent prefers losing under transparency to losing under non-transparency.

The incumbent's preference for non-transparency, $E U_{I}(N T) \geq E U_{I}(T)$, boils down, after simplification, to a condition on the probability that the opposition leader is compromised:

$$
\mu \geq \bar{\mu}=2-2 \frac{-x_{O}^{E}+\frac{1}{2 \delta}}{\theta\left(x_{O}^{M}-x_{O}^{E}\right)} .
$$

Proposition 4 states formally the existence and comparative statics results for the case of an uncertain position of the median voter.

Proposition 4 (i) For any incumbent's ideal point $x_{I}$, opposition ideal points $x_{O}^{M}$ and $x_{O}^{E}$, and the probability of the opposition being moderate $\theta$, there exists a critical probability that the opposition leader is compromised, $\bar{\mu} \geq 0$, defined in (6) such that for any $\mu \geq \bar{\mu}$, the incumbent will prefer to refrain from a transparency regime.

(ii) The threshold $\bar{\mu}$ is increasing, making the range for transparency regime parameters wider, with the probability that the challenger is moderate, $\theta$, and the uncertainty regarding the median voters' ideal point $(\delta)$. As the distance between $x_{O}^{M}$ and $x_{O}^{E}$ increases, the range for transparency regimes becomes narrower.

The first part of Proposition 4 states that for higher levels of compromised opposition challengers, the incumbent will prefer non-transparency. Hence, relaxing the assumption that the 
median voter's position is known does not weaken the result demonstrated earlier: the more compromised politicians there are, the less likely we are to see a transparency regime put in place. The fact that the more likely it is that the opposition is compromised, the higher the chances that moderate leaders will behave like extreme leaders and make themselves unattractive to the median, preserving the incumbency advantage is theoretically intuitive. Yet the robustness of this result is disturbing from a normative point of view. When there is a greater number of compromised politicians in the political system, the need for transparency is greater, but it is under these precise circumstances when compromised politicians are left unexposed.

The second part of the proposition describes what affects the critical level of kompromat above which the incumbent will choose non-transparency. What increases the threshold is the proportion of moderate opposition challengers; what decreases the threshold is uncertainty around the median. These comparative statics results are also intuitive. When there is a higher proportion of moderate opposition challengers, the median voter sacrifices more by reelecting the incumbent (recall that he prefers by assumption a moderate opposition challenger to the incumbent as long as he is not compromised). At the same time, an increase in the distance between the two opposition challengers decreases the threshold, which makes non-transparency more prevalent. This is intuitive as the fall out from compromised politicians is more dramatic when the swing to mimic the extreme opposition challenger is greater. The incumbent exploits the median voter's fear that voting for the opposition might place policy considerably further away from the median voter's ideal point.

\subsection{Heterogeneous Opposition}

A potential limitation of the baseline setup analyzed above is that it assumes that the incumbent and the blackmailing security officer have ideal points on opposite sides of the median voter. Why would a former autocrat and a security officer who used to work for that former autocrat have such divergent preferences?

It is important to point out that since the period under investigation is post-authoritarian, there is no reason to expect that the ideal points of the former security apparatus worker with access to sensitive information and of the incumbent should be proximate to each other. ${ }^{14}$ However, to

\footnotetext{
${ }^{14}$ Another justification for the assumption of divergent preferences between the blackmailer and the incumbent identifying with the successor party is based on the work of Chestnut Greitens (2017). According to Chestnut Greitens, the main threat faced by the autocrat is from members of the ruling coalition. Coup-proofing concerns
} 
check the robustness of our baseline model, in this subsection, we relax the assumption and model the blackmailer and incumbent with ideal points on the same side of the median voter.

The timing and nature of electoral competition are exactly as before with the precise preferences of the incumbent known but four cross-cutting types characterizing the opposition challenger. The position of the median voter is known and located at $x_{m}=0$, as in the baseline model. However, in a departure from the baseline, we now assume that the ideal policy of the challenger is represented by a far left challenger or a moderate right challenger. In sum, $x_{B}<x_{O}^{L}<x_{I}<0<x_{O}^{R}$. For symmetry, the position of the incumbent is moderately left, but we still focus on the range of parameters for which the incumbent would lose elections to the right-wing type of the opposition leader. That is, assuming $\left|x_{I}\right|>\left|x_{O}^{R}\right|{ }^{15}$

But for the subscripts characterising the players, the analysis is identical to the baseline model from section 3. However, the conditions previously expressed in (1) now become equivalent to:

$$
\begin{gathered}
-x_{I}<-x_{O}^{L}(\theta+(1-\theta) \mu)+x_{O}^{R}(1-\theta)(1-\mu) \\
-x_{O}^{L} \theta+x_{O}^{R}(1-\theta)<-x_{I} .
\end{gathered}
$$

Beginning with (8), note that by assumption $x_{O}^{R}<-x_{I}$. Thus, there exists $\widetilde{\theta}>0$ such that for any $\theta \in[0, \widetilde{\theta}]$, condition (8) is fulfilled. Now, fix any such $\theta \in[0, \widetilde{\theta}]$. As $-x_{O}^{L}>-x_{I}$, by assumption, there exists $\widetilde{\mu}=\widetilde{\mu}(\theta)<1$ such that for any $\mu \in[\widetilde{\mu}, 1]$, condition (7) is fulfilled. Thus, for any pair of parameters $(\theta, \mu)$ such that $\theta \in[0, \widetilde{\theta}], \mu \in[\widetilde{\mu}(\theta), 1]$, the incumbent will prefer no transparency. Moreover, as before, it is straightforward to see that an increase in $\mu$ will make satisfying (7) easier for any $\theta$ that satisfies (8). That is, we have demonstrated that the main results of our baseline model hold for a range of parameters when the blackmailer is not necessarily on the same side of the political spectrum as the victim of the blackmail.

incentivize autocrats to refrain from creating a centralized security agency. Instead, she creates a collection of competing agencies, frequently with overlapping jurisdictions. As the agencies check each other and compete for favors with the autocrat, neither rises to be a threat to her power. Under these circumstances, it is not surprising to see a blackmailer on the opposite side of the median voter relative to the incumbent.

${ }^{15}$ For scholars familiar with the post-communist cases, this set-up resembles a situation with a ("reformed communist") as the incumbent, a security officer with hard-line preferences associated with the previous era, and a very heterogeneous opposition. Poland, Hungary, and Bulgaria in the 1990's match this context very well. 


\subsection{A Compromised Incumbent}

We now consider an extension where the incumbent, who decides on the transparency regime, might be compromised. In light of this, the choice of the transparency regime itself becomes a signal of the incumbent's type. Hence, a compromised incumbent will not choose transparency. Does that imply that an incumbent who is not compromised will implement transparency? Naive intuition suggests that opening secret police archives offers the incumbent the opportunity to differentiate herself from the compromised type and, therefore, should be the more attractive option, as voters can only improve their perception of her.

Yet we show that to the contrary: the uncompromised incumbent may too be better off without transparency, even though without transparency, voters improve their perception of her opponent. Uncompromised incumbents will balance these competing considerations. We consider this extension another robustness check of our baseline model, as it proves we do not have to assume that incumbents never have skeletons in the closet to show that uncompromised incumbents refrain from transparency.

Model uncertainty about the incumbent's type requires not only a typespace including a compromised and uncompromised type, but also a cross-cutting typespace over policy preferences. This is necessary because were citizens to observe an incumbent choosing a policy that no uncompromised incumbent would pick, they would know instantly they are dealing with a compromised incumbent. Successful blackmail requires that uncompromised incumbents be allowed to choose the same policy that a blackmailed compromised incumbent would.

We assume first, that the incumbent is one of two possible types: the first with ideal point

$x_{I}^{M}>0$, occurring with probability $\alpha$; and the second-with ideal point $x_{I}^{E}<0$, occurring with probability $1-\alpha$. We assume further that the incumbent is compromised with probability $\lambda$. Besides two modifications, the game is the same as described in our baseline model: First, the incumbent, upon winning, has to choose policy; we denote her optimal choice $x_{I}^{*}$. Second, the voters form their beliefs as to the type they are facing once they observe the elected politician's policy choice, be it the opposition leader or the incumbent. As in the baseline model, we restrict our attention to the perfect equilibria that survive the intuitive criterion. This assumption, recall, guarantees that, when choosing policy, uncompromised politicians refrain from dominated strategies. 
We conduct our analysis backwards. If the winner of the election chooses any policy other than $x_{I}^{M}, x_{I}^{E}, x_{O}^{M}$, or $x_{O}^{E}$, voters learn with certainty that she is compromised and remove her from office. Otherwise, as in the baseline model, the politician is retained baring the publication of kompromat. Hence, there is a unique perfect Bayesian equilibrium that satisfies the intuitive criterion: the uncompromised incumbent and opposition leader, if elected, choose their respective ideal policies; the compromised incumbent, following elections, chooses $x_{I}^{*}=x_{I}^{E}$ regardless of her policy type; the compromised opposition leader chooses $x_{O}^{*}=x_{O}^{E}$. Thus, under transparency, the incumbent is elected as long as $E u_{m}\left(x_{I}^{*} \mid T\right)=-\alpha x_{I}^{M}+(1-\alpha) x_{I}^{E}$ exceeds $E u_{m}\left(x_{O}^{*} \mid T\right)=\theta x_{O}^{M}+(1-\theta) x_{O}^{E}$. Under non-transparency, the incumbent is elected as long as $E u_{m}\left(x_{I}^{*} \mid N\right)=-\alpha(1-\lambda) x_{I}^{M}+(1-\alpha+\alpha \lambda) x_{I}^{E}$ exceeds $E u_{m}\left(x_{O}^{*} \mid N\right)=\theta(1-\mu) x_{O}^{M}+(1-\theta+\theta \mu) x_{O}^{E}$. A pooling equilibrium, in which both types of incumbent, the compromised and non-compromised, refrain from transparency, exists if both of following the conditions are fulfilled simultaneously:

$$
\begin{aligned}
& -\alpha x_{I}^{M}+(1-\alpha) x_{I}^{E} \leq \theta x_{O}^{M}+(1-\theta) x_{O}^{E}, \\
& -\alpha(1-\lambda) x_{I}^{M}+(1-\alpha+\alpha \lambda) x_{I}^{E} \geq \theta(1-\mu) x_{O}^{M}+(1-\theta+\theta \mu) x_{O}^{E} .
\end{aligned}
$$

Solving the system, we can demonstrate that there is a range of parameters $\alpha$ and $\lambda$, for which there exists a pooling equilibrium. Although implementing the transparency regime is an opportunity for the incumbent to signal to voters that she is not compromised, she sometimes prefers to choose non-transparency. Non-transparency makes her less attractive to voters than transparency would, but it hurts the opposition even more. Figure 7 depicts one such situation, where the median voter prefers the opposition under transparency, but when presented with the choice of a perhapscompromised incumbent and a perhaps-compromised opposition leader, chooses the former. This is represented in the figure by the blue area being completely enclosed by the red area. Proposition 5 states this result formally.

Proposition 5 There exist two thresholds $\bar{\alpha}<1$ and $\bar{\lambda}>0$ such that for any probability of extreme policy preferences $\alpha>\bar{\alpha}$ and probabiity of kompromat $\lambda<\bar{\lambda}$, there exists a pooling equilibrium where both types of the incumbent, compromised and non-compromised, choose a non-transparency regime.

Thresholds $\bar{\alpha}$ and $\bar{\lambda}$ described in Proposition 5 are functions of parameters of the model, ideal 


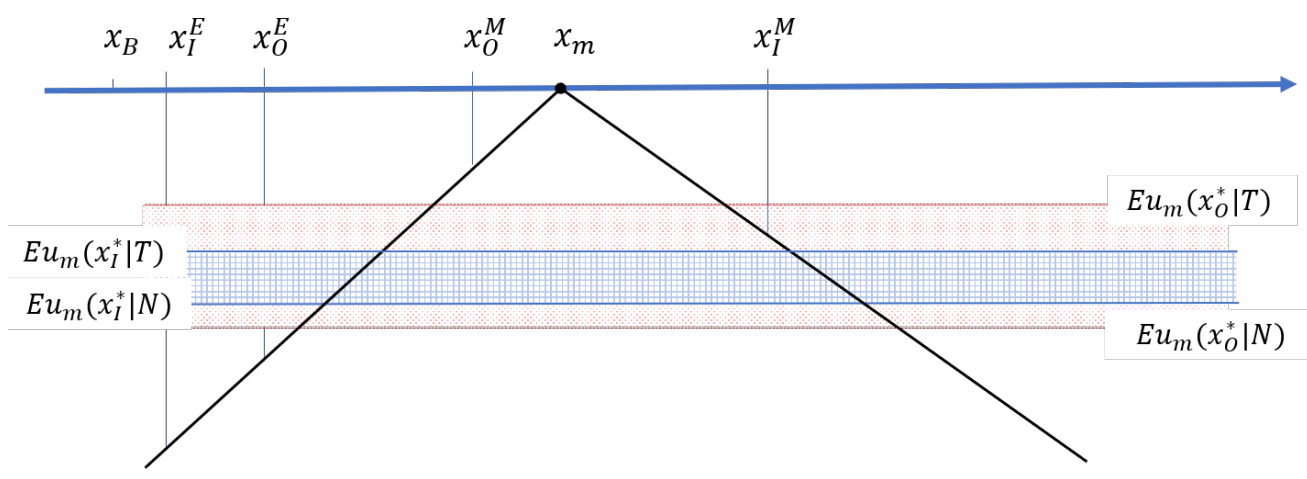

Figure 7: The median voter prefers the opposition leader under transparency $\left(E u_{m}\left(x_{I}^{*} \mid T\right)<E u_{m}\left(x_{O}^{*} \mid T\right)\right)$, but chooses the incumbent when confronted with the choice between a "maybe-compromised" incumbent and "maybecompromised" opposition leader $\left(E u_{m}\left(x_{I}^{*} \mid N\right)>E u_{m}\left(x_{O}^{*} \mid N\right)\right)$.

points of all incumbent's and opposition leader's types $\left(x_{I}^{M}, x_{I}^{E}, x_{O}^{M}, x_{O}^{E}\right)$, the median voter's position, which is normalized to $x_{m}=0$, and the probabilities that the opposition leader is moderate, $\theta$, or compromised, $\mu$.

We can also derive intuitive comparative statics predictions: the range of parameters for which the pooling equilibrium exists increases as the threshold $\bar{\alpha}$ decreases and $\bar{\lambda}$ increases, that is, when the probability of opposition kompromat, $\mu$, increases, or the extreme position of the opposition, $x_{O}^{E}$, shifts left. Critically, the results described in this subsection are not "limit" results: they hold for a range of parameters, further demonstrating the robustness of the baseline model.

\section{Transparency Regimes in Post-Communist Europe}

In this section, we focus on corroborating with empirical evidence a few hypotheses derived from the empirical implications of the model above. The key overall expectation is that incumbent politicians who themselves are not compromised will under fairly broad circumstances refrain from implementing transparency regimes. But when are politicians in office not compromised? We argue that such conditions have obtained in Post-Communist Europe, where successor communist parties have, on a number of occasions, secured enough legislative seats to lead cabinets after 1990 (the year by which a majority of these countries had transitioned to democracy).

Earlier ethnographic work carried out by one of the authors corroborates this assumption. During semi-structured interviews conducted in Poland in 2003/2004 among tens of former politicians and dissidents, many indicated that the efforts of the authoritarian security police were directed 
at infiltrating what used to be the anti-communist opposition. Of the quotes below all but one are actually attributed to former dissidents. According to a former Minister of Interior interviewed in Warsaw, Poland, "the Secret Police was not allowed to recruit [communist] party members; that is why lustraton mostly hurts the liberal opposition." 16 Another respondent insisted that "the secret police was interested exclusively in recruiting dissidents who are now in the opposition" 17 One respondent mentioned the presence of collaborators in the context of a question about the destruction of secret police files at the time of transition to democracy: "Of course there were collaborators among the ranks of Solidarity and the evidence is still there, because if the communists destroyed anything on their way out, it was evidence of their own involvement." 18 One respondent tried even to excuse dissidents successfully recruited for collaboration by saying "Yes, the top leadership of the liberal opposition was infiltrated - there is not doubt about that, but often the recruitment itself was the effect of blackmail, not bribing them with perks." ${ }^{19}$ Finally, to the extent that the successor communists were infiltrated at all, the revelation of skeletons in the closet was by far a greater blow to members of the opposition, because "in their circles, uncovering someone as a collaborator led to deleting him or her from your Rolodex." 20 Taken together, this qualitative evidence corroborates our assumptions about the close to non-existent collaboration of the successor communist incumbents with the secret police.

In addition, the Post-Communist scenario pertains to the situation where both leaders of the opposition are on the same (right) side of the median voter in a general left-right policy space, with the successor communist party on the left side of the median.

The first expectation we formulate based on our model is to see fewer transparency regimes when successor communist incumbents are leading cabinets than when they are in the opposition.

As a second step, we refine this expectation in line with the comparative static expressed in Proposition 2. Recall that according to this proposition, there exists a critical point in the issue

\footnotetext{
${ }^{16}$ Interview conducted January 20, 2004 with former Mister of Interior, member of Freedom Union, UW at ul. Wislana 12, in Cracow, Poland, code L6 (identifying information on file with author.)

${ }^{17}$ In February of 2004, the former communist party, SLD, was leading the cabinet coalition and hence the "opposition' in this quote indeed corresponds to the opposition from our model. This specific interview was conducted February,1 2004 with a member of Freedom Union, UW ode L7 (identifying information on file with author).

${ }^{18}$ Interview conducted February 1, 2004 in Poland, member of Freedom Union, UW, code L12 ( identifying information on file with author).

${ }^{19}$ Interview conducted January 20, 2004 with former Mister of Interior, member of Polish Peoples' Party, in Cracow, Poland, code C4 (identifying information on file with author.)

${ }^{20}$ interview was conducted February, 42004 with a member of Civic Platform, PO code L9 (identifying information on file with author).
} 
space such that for any moderate leader of the opposition to the right of that point, the incumbent stands to benefit from a non-transparency regime over a transparency regime. Hence, we expect that as the moderate opposition leader becomes more moderate, transparency regimes become delayed or are replaced by non-transparency regimes.

As a third step, we refine this expectation in line with the comparative static expressed in Proposition 3, according to which there exists a range of incumbents that will benefit from a nontransparency regime relative to a transparency regime. This range characterizes an incumbent that is neither too moderate nor too extreme.

We illustrate these regularities with data on transparency regimes and party positions, supplemented with data on vote shares and governing status.

We do not illustrate all of our theoretical results. For instance, we do not test hypotheses corresponding to Proposition 4. Based on this proposition, we expect that as the proportion of collaborators among the opposition increases, the implementation of transparency regimes will be delayed, or these regimes will be replaced by a non-transparency regime. The reason we do not attempt to collect data on the proportion of former secret police collaborators among the opposition (represented in the model as $\mu$ ) is that ultimately, this data is too difficult to find. Since the nature of this collaboration with the authoritarian regime is secret, unless a transparency regime is established, we have no evidence that collaboration took place. Hence, the comparative static with respect to the proportion of collaborators remains a purely theoretical result.

\subsection{Operationalization of Model Parameters}

In order to test the hypotheses outlined above, we propose variables to operationalize:

1. Whether the incumbent has selected a transparency regime or is retaining post-authoritarian non-transparency (represented in the model by the difference in the incumbent's expected payoff under the non-transparency and transparency regimes: $\left.E U_{I}\left(x_{O}^{*} \mid N\right)-E U_{I}\left(x_{O}^{*} \mid T\right)\right)$;

2. How moderate the opposition leader closer to the median is ( $x_{O}^{M}$ in the model);

3. How moderate or extreme the incumbent is (represented in the model by $x_{I}$ ).

As explained above, we limit our universe of cases to Post-Communist countries where we believe that the proportion of secret collaborators should be relatively similar. These are European 


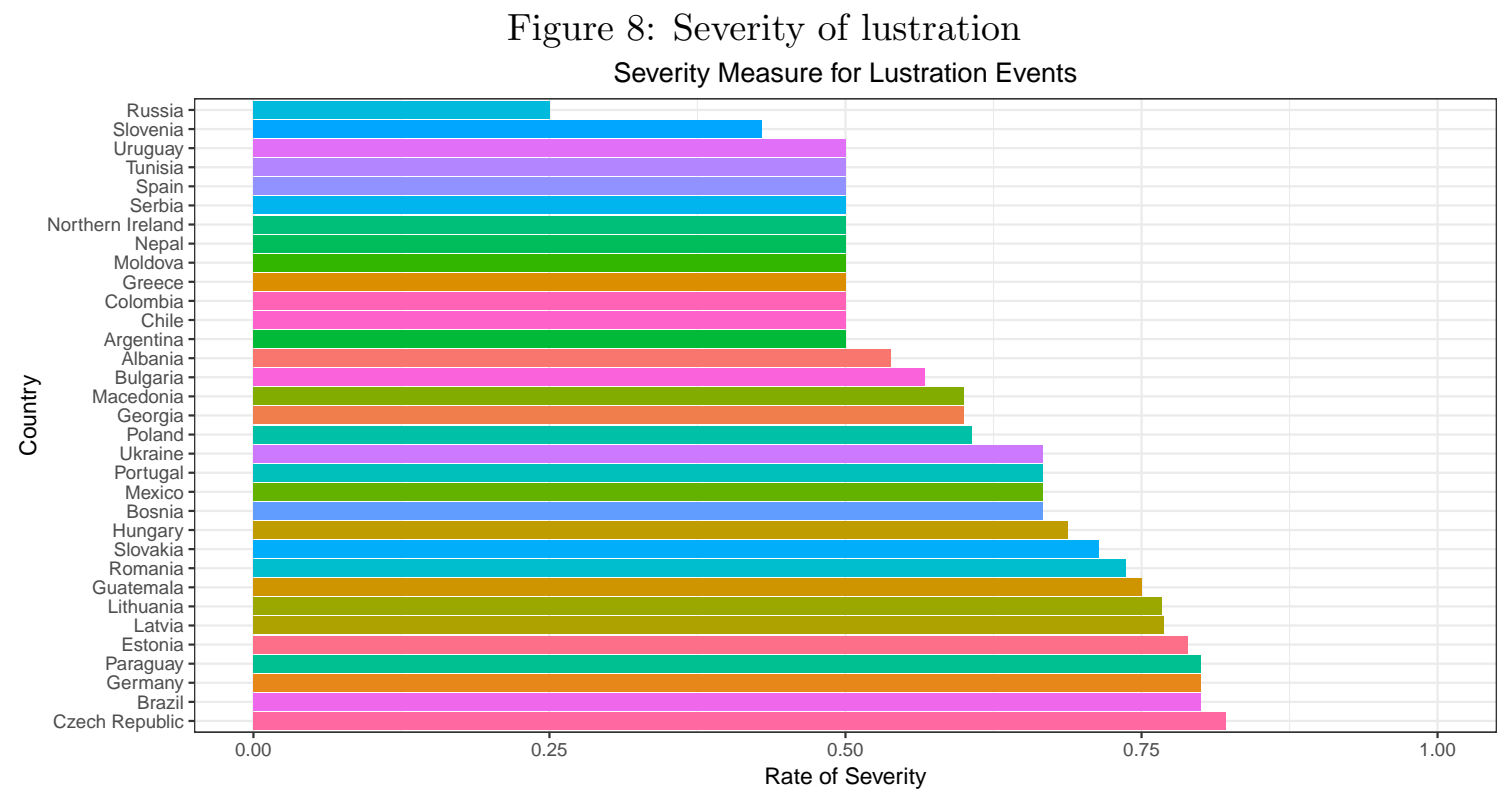

Post-Communist countries that remained under the Soviet influence from 1946 through 1989 and were later admitted to the EU: Poland, Hungary, Slovenia, Bulgaria, Estonia, Latvia, Lithuania, Romania, Croatia, the Czech Republic, and Slovakia.

Our data come from several sources. The first is the Global Transitional Justice Dataset (GTJD). This dataset will be the source of our key dependent variable, the change in transparency from a more transparent to a less transparent regime. The GTJD is a time series created for 84 countries that transitioned to democracy from authoritarianism or civil war between 1946 and 2016 . From this set, we present the 11 Post-Communist countries alongside 50 other countries that transitioned from authoritarian rule (thus, excluding Post-Conflict cases of transparency). The rationale behind this restriction is that only formerly authoritarian countries will have successor authoritarian parties, who-we argue - illustrate the incumbents that are certain to not have kompromat against themselves. To measure the level of transparency, we use GTJD's "severity of lustration" variable (Bates, Cinar and Nalepa, 2020).

Figure 8 below reports lustration severity for those countries in the Global Transitional Justice Dataset that had a score greater than zero.

Our severity scores were originally developed by Ang and Nalepa (2019) as a measure of transitional justice intensity. This variable provides a transparency score between 0 and 1 for each of the 61 post-authoritarian countries. It was created by coding as an annual panel all lustration-related 
events, taking into consideration whether they move the transparency process forward (positive events, represented by $P$ ) or backward (negative events, represented by $N$ ). It is defined as

$$
S=\frac{\sum_{T=0}^{N} P_{T}}{\sum_{T=0}^{N}\left(P_{T}+N_{T}\right)+1}
$$

where $T=N$ is 2016 or the last year of the democratic spell before the country's reversal to authoritarian rule, ${ }^{21}$ and $T=0$ is the first year following the country's transition.

$S$ assumes the value of zero when a country has no positive TJ events or when a country has had exactly as many positive events as negative events. The measure will approach the value of 1 as more events are positive relative to all events; it will approach 0 as more events in the dataset are negative.

Figure 8 shows that there is considerable variation among transparency regimes across PostCommunist cases, from low values of severity in Slovenia and Croatia (the latter is not even listed, as it had zero lustration events, and severities of zero have been omitted from the figure) to high values in Estonia and Latvia, which have some of the most extreme severity scores of all postauthoritarian states.

Additionally, Figure 8 illustrates why collecting transparency regime data as a time series is justified. Transparency regimes may be implemented in the immediate aftermath of transition (Elster, 2004), but they may also be significantly delayed. Indeed, the presence of countries with delayed transitional justice in the figure indicates just how much information would be sacrificed by ignoring transparency regimes implemented decades following the transition. ${ }^{22}$

The second source of our data is the Chapel Hill Expert Survey, from which we have obtained information about political parties, their positions on the general left-right dimension, their vote share, and their government status. We collected data on policy positions in electoral terms between 1991 and 2017. The total number of such party-terms was 577. Of these, 20 cases offered insufficient

\footnotetext{
${ }^{21} N$ need not be the same as 2016 , as illustrated by the case of Thailand, which experienced a military coup in 2014 .

${ }^{22}$ Among the countries where one had to wait long for transparency regimes to be implemented are Spain, where the 1977 Amnesty Law prevented any attempts to uncover atrocities committed by the Franco regime (Aguilar, 2012), and Colombia, where human rights violations associated with the civil war were not prosecuted and were kept secret long enough to warrant an open letter published in daily newspapers by the Office of the Prosecutor of the ICC (Urueña, 2017). Similarly, in Northern Ireland, skeletons in the closet from the time of the so-called "Troubles" were sealed to remain secret as part of the peace process known as the Good Friday Agreements. Even more interestingly, these promises remained enforced even following the demobilization of the rebels and the withdrawal of paramilitaries (Rolston, 2006).
} 
data to reconstruct a complete electoral term, so they were dropped. ${ }^{23}$

This procedure produces 23 electoral terms during which a Post-Communist incumbent was in office. Of these, in three instances, CHES data was only available for one other party in addition to the incumbent (Croatia's 1990 term, Bulgaria's 1990 term, and Bulgaria's 1991 term).

For the remaining 20 cases, for each country-term, we located the position of the incumbent and the median on the left-right dimension (based on the positions of all parties for which experts were surveyed in that term), and the positions of the two opposition parties with the two highest vote shares. The opposition party closest to the median was labeled the moderate opposition, corresponding to $x_{O}^{M}$ in the model; the opposition party farther away from the median was labeled the extreme opposition, corresponding to $x_{O}^{E}$ in our model.

Finally, we use the GTJD to measure severity of transparency regimes, focusing on lustration in the four-year intervals corresponding to the CHES survey intervals. These severity scores are then compared to equivalent severity scores during periods when authoritarian incumbents were out of office (by taking the average). A comparison consistent with our model's predictions is a severity score that is lower when the successor communist party is the incumbent. Of the 20 cases, 13 are consistent with this prediction, three are inconsistent, and another three did not satisfy a key assumption of the model (having a viable moderate opposition). The results are summarized in Figure 9 below.

In order to account for $\theta$, we also record the votes share of both opposition parties. This exercise again led us to curtail our set of cases further. Of the three cases incompatible with our model, we eliminated two more based on the following reasoning: although the moderate opposition was moderate enough, its vote share was so low relative to that of the extreme opposition party that comparative statics on $\theta$, expressed in the analysis leading up to Proposition 3 , would lead us to moderate our expectation regarding maintaining a non-transparency regime. Indeed, in these circumstances, chances of the moderate opposition winning are so slim that the incumbent has nothing to lose from a transparency regime.

The eliminated cases in question are Lithuania in 2006 and Poland in 1996. In Lithuania in 2006, the moderate opposition was farther away from the median than the incumbent (1.23625 in

\footnotetext{
${ }^{23}$ The CHES expert survey only asks experts about the positions of the most popular parties, but for several Post-Communist electoral terms, those parties were not actually the ones to receive the highest vote share.
} 
contrast to 1.09625); in Poland in 1996, the opposition was also not very moderate compared to the incumbent. This meant that the incumbent in all likelihood did not have to avoid a transparency regime in order to secure reelection. Indeed, in 1997, the successor communist party passed a lustration law. Two more cases that do not fit the model's restrictions are Bulgaria in 2006 and Lithuania in 2002. In Bulgaria in 2006, the opposition was moderate (with a distance to the median of 0.342857$)$, but the incumbent was extreme to the right (2.427143). According to Proposition 3 in such a situation, the incumbent loses anyway-with or without a transparency regime. This is indeed what happened. 2006 was the final year when BSP was in office. In Lithuania in 2002, the vote share of the moderate opposition was very low compared to that of the extreme opposition. In light of such a low $\theta$ (in the language of our model), the incumbent would not need a transparency regime to avoid the threat from the moderate opposition because this threat was already low. Indeed, during that term, the Lithuanian incumbents passed a lustration law; this is reflected in our data.

After eliminating from consideration these additional cases, Figure 9 summarizes the ones that comply with our predictions. The sub-figure headings feature the country name, year of the electoral term, and the difference in transparency regime severity between terms when the incumbent was the successor communist party and when a different incumbent was in office. The data used to create this figure are provided in the empirical appendix.

After accounting for the nuances of our model - such as the effects of $\theta$, the probability that the opposition is moderate rather than extreme, and the effects of the location of the moderate opposition vis á vis the location of the incumbent - we are left with fourteen cases that are fully compliant with the conditions of our model: these cases are represented in Figure 9. Of those fourteen, the severity of transparency was lower when incumbents were in office in thirteen electoral terms. The only case that does not fit our predictions is Hungary in 2002, where the successor communist $\mathrm{MDSz}$ embarked on a transparency regime campaign despite our predictions that it should refrain from doing so. Yet, the motivation behind Hungary's lustration law was very specific. Early in 2001, after the Hungarian Socialist Party secured an electoral victory, Magyar Nemzet, a leading Hungarian daily, broke the news that Peter Medguessy, the newly appointed Prime Minister, had collaborated with the secret police under communism. While this was true, in order to clear his name - or rather, to present his collaboration in a more favorable light - his party passed a law 
exposing all collaboration with the secret police by other politicians. Following the revelations, as predicted, Medgyessy's act indeed appeared less controversial. In light of these events, we believe that this one instance where the empirical events do not corroborate our model's story is not an insurmountable problem for the logic behind the adoption of transparency regimes we propose.

Before turning to the conclusion, it is worth reflecting on the kind of empirical test, corroboration, or even illustration that our theoretical model allows. Our theoretical analysis takes place at the level of political leaders. Such leaders only have the opportunity to implement or not implement transparency regimes when in power. A change in leadership can occur every four years, and we are limited to countries that are post-authoritarian. In addition, our model places restrictions on the kinds of cabinets that fulfill our predictions. First, they must be led by incumbents who are certain to not have skeletons; second, there must be uncertainty about the ideal point of the opposition challenger, a situation that is only possible when there are at least two such viable opposition parties. Above, we have shown how from a universe of 577 parties, the set of cases for which we can formulate precise predictions reduces to just 14 cabinets. This set is obviously too small to run large-n regressions. At the same time, it should not excuse researchers from the pressure of providing evidence. Our medium-n analysis has a clear advantage over case study analysis that "cherry picks" cases so the narrative matches the model. It also has an advantage over large-n analysis, which would require us to include units of analysis that clearly do not match the model's restrictions.

\section{Conclusion}

Transparency regimes are rare even though they are frequently less costly than punitive or compensatory forms of transitional justice. Revealing the truth on secret authoritarian legacies should be easier than holding trials of perpetrators of human rights violations or compensating victims for harm they suffered or for property expropriated from them. Yet, in the aftermath of transitions to democracy, we see considerably fewer attempts to lustrate and create truth commissions than to implement trials and purges.

This is puzzling in light of the fact that some political actors should stand to gain from revealing skeletons in the opposition's closet (specifically, these are the actors not tainted by kompromat). In 
this paper, we present a mechanism that can account for the delay or even absence of transparency regimes. Our argument rests on the electoral advantage that uncompromised incumbents gain when they allow compromised challengers to be blackmailed by those who threaten to reveal kompromat. Blackmailers originating in the former security apparatus extort policy concessions from challengers who have skeletons in the closet; these policy concessions make the challengers so unattractive to the median voter that the incumbent is able to solidify his power. Simply put, there is an advantage to having voters believe that any opposition politician might be compromised. It is harder to compete against clean politician, so allowing the actually compromised politicians to be outed hurts incumbents.

We show that non-transparency regimes are more likely to persist when the proportion of collaborators from the former authoritarian regime is large and as the moderate opposition challenger moves closer to the median voter and is more likely to include secret police collaborators. The first result is robust to changing the structure of the players' ideal points, and both are robust to introducing uncertainty around the specific location of the median. Moreover, out results do not even require that the incumbent be completely free of skeletons in the closet.

Our results explain the puzzling restraint of successor authoritarian parties in revealing to the electorate that the heroes of the democratic transition were infiltrated by agents of the former security apparatus. This explanation is more general than strategic preemption or the "slippery slope" hypothesis, whereby lustrations and truth commissions would morph into punitive forms of transitional justice that could hurt successor autocrats. Perhaps the most striking normative implication of our model is that the more likely the opposition is to be compromised, the higher the chances that kompromat is effective and preserves incumbency advantage. This unsettling result means that the greater the normative needs for transparency-because of a greater number of compromised politicians - the less likely compromised politicians are to be exposed. In other words, countries that need transparency the most are least likely to get it. 

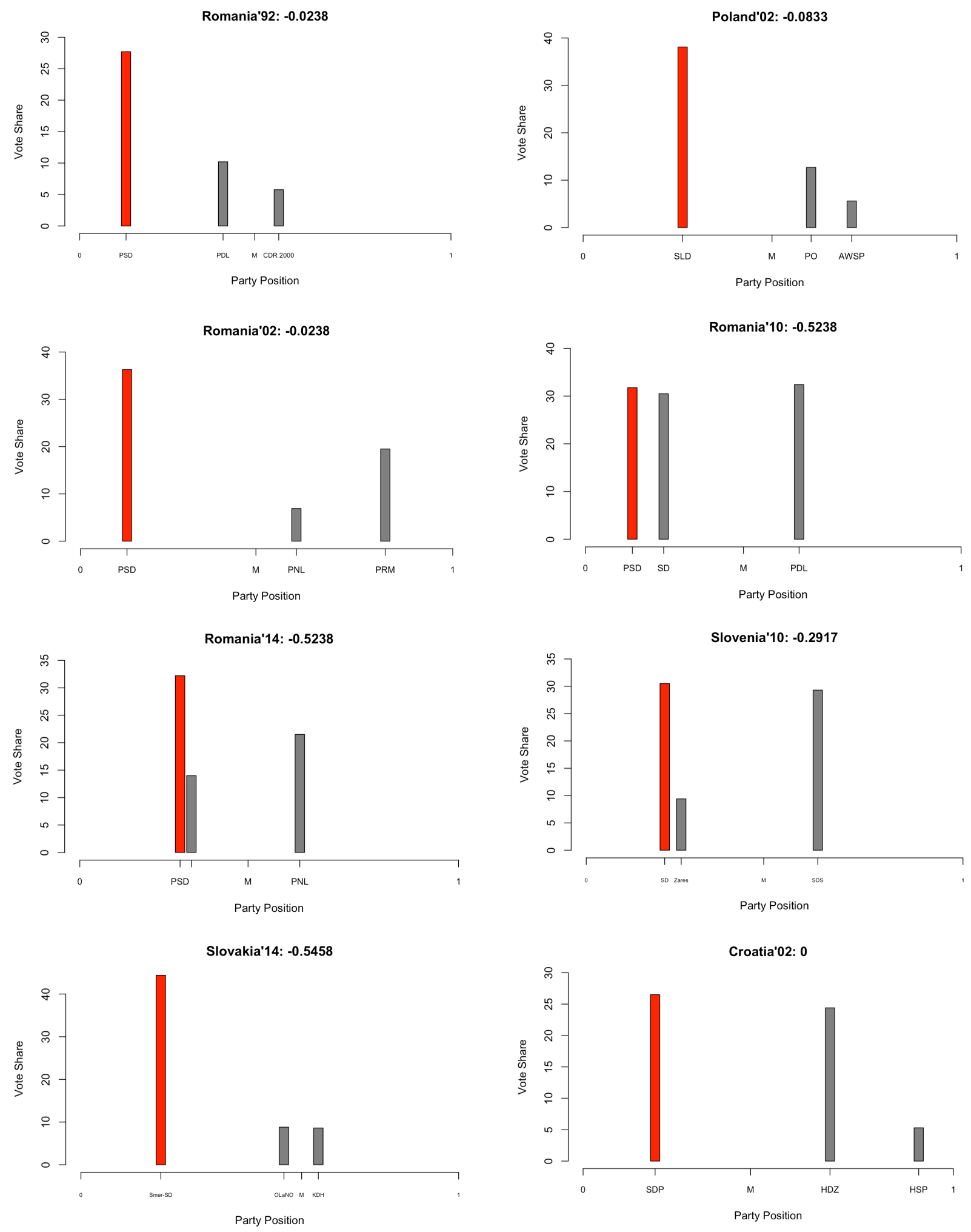

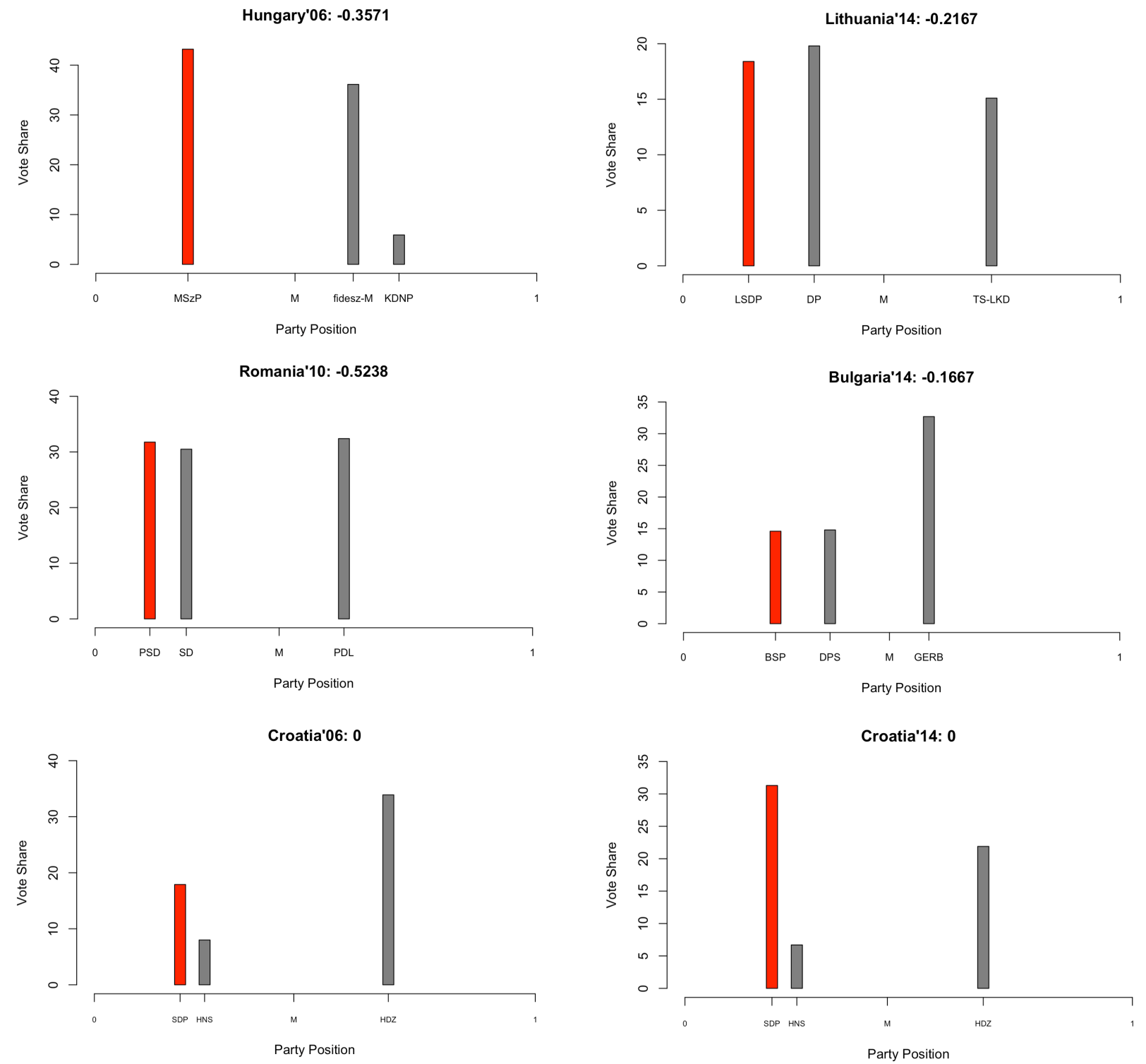

Figure 9: vote shares and locations in the general left-right policy space of successor communist incumbents (to the left of the median, M) and two opposition challengers: moderate and extreme 


\section{References}

Aguilar, Paloma. 2002. Memory and amnesia: The role of the Spanish Civil War in the transition to democracy. Berghahn Books.

Aguilar, Paloma. 2012. "The Spanish Amnesty Law of 1977 in Comparative Perspective." Amnesty in the Age of Human Rights Accountability: Comparative and International Perspectives 29:315.

Aguilar, Paloma, Laia Balcells and Héctor Cebolla-Boado. 2011. "Determinants of attitudes toward transitional justice: An empirical analysis of the Spanish case." Comparative Political Studies 44(10):1397-1430.

Albertus, Michael and Victor Menaldo. 2014. "Gaming democracy: elite dominance during transition and the prospects for redistribution." British Journal of Political Science 44(3):575-603.

Ang, Milena and Monika Nalepa. 2019. "Can transitional justice improve the quality of representation in new democracies?" World Politics 71.

Bates, Genevieve, Ipek Cinar and Monika Nalepa. 2020. "Accountability by Numbers: A New Global Transitional Justice Dataset (1946 - 2016)." Perspectives on Politics 18(1):161 - 184.

Binningsbo, Helga Malmin, Cyanne E Loyle, Scott Gates and Jon Elster. 2012. "Post-Conflict Justice Dataset Codebook." Center for the Study of Civil War.

Blaydes, Lisa. 2010. Elections and distributive politics in Mubarak's Egypt. Cambridge University Press.

Cenckiewicz, Slawomir and Piotr Gontarczyk. 2008. SB a Lech Walesa: przyczynek do biografii. Vol. 40 Instytut Pamieci Narodowej.

Cepl, Vojtech. 1992. "Ritual sacrifices." East European Constitutional Review 1:24.

Cho, In-Koo and David M. Kreps. 1987. "Signaling Games and Stable Equilibria." The Quarterly Journal of Economics 102(2):179-221.

Clark, Terry D. and Egle Verseckaite. 2005. "PaksasGate : Lithuania Impeaches a President." Problems of Post-Communism 52(3):16-24.

Coase, Ronald. 1988. "Blackmail." Virginia Law Review 4:655-676.

Dragu, Tiberiu and Adam Przeworski. 2019. "Preventive repression: Two types of moral hazard." American Political Science Review 113(1):77-87. 
Dragu, Tiberiu and Yonatan Lupu. 2018. "Collective action and constraints on repression at the endgame." Comparative Political Studies 51(8):1042-1073.

Ellsberg, Daniel. 1968. "The Theory and Practice of Blackmail." Rand Corporation Working Paper 3883 .

Elster, Jon. 2004. Closing the books: Transitional justice in historical perspective. Cambridge University Press.

Elster, Jon. 2012. "Justice, truth, peace." Nomos 51:78-97.

Grzymala-Busse, Anna M. 2002. Redeeming the communist past: The regeneration of communist parties in East Central Europe. Cambridge University Press.

Helmke, Gretchen, YeonKyung Jeong and Seda Ozturk. 2019. "Upending Impunity: Prosecuting Presidents in Contemporary Latin America." Workshop Upending Impunity University of Chicago.

Holmes, Stephen. 1994. "The end of decommunization." E. Eur. Const. Rev. 3:33.

Hubert, Ryan and Andrew Little. 2019. "Kompromat." unpublished manuscript pp. 1-45.

Huntington, Samuel P. 1993. The third wave: Democratization in the late twentieth century. Vol. 4 University of Oklahoma press.

Karklins, Rasma. 2002. "Typology of post-communist corruption." Problems of post-communism $49(4): 22-32$.

Karklins, Rasma. 2005. The system made me do it: corruption in post-communist societies. ME Sharpe.

Krcmaric, Daniel. 2018. "Should I Stay or Should I Go? Leaders, Exile, and the Dilemmas of International Justice." American Journal of Political Science 62(2):486-498.

Los, Maria. 2003. "Crime in transition: The post-communist state, markets and crime." Crime, Law and Social Change 40(2-3):145-169.

Loyle, Cyanne E and Benjamin J Appel. 2017. "Conflict Recurrence and Postconflict Justice: Addressing Motivations and Opportunities for Sustainable Peace." International Studies Quarterly 61(3):690-703. 
Magaloni, Beatriz. 2006. Voting for autocracy: Hegemonic party survival and its demise in Mexico. Vol. 296 Cambridge University Press Cambridge.

Myerson, Roger B. 1990. Game theory. Harvard university press.

Nalepa, Monika. 2010. Skeletons in the closet: Transitional justice in post-communist Europe. Cambridge Studies in Comparative Politics Cambridge University Press.

Offe, Claus. 1992. "Coming to terms with past injustices: an introduction to legal strategies available in post-communist societies." European Journal of Sociology/Archives Européennes de Sociologie/Europäisches Archiv für Soziologie 33(1):195-201.

Olsen, Tricia D, Leigh A Payne and Andrew G Reiter. 2010. "The justice balance: When transitional justice improves human rights and democracy." Human Rights Quarterly 32(4):980-1007.

Paine, Jack. 2019. "The Loyalty-Efficiency Tradeoff in Authoritarian Repression.".

Penn, Elizabeth Maggie. 2016. "Engagement, disengagement, or exit: A theory of equilibrium associations." American Journal of Political Science 60(2):322-336.

Posner, Robert. 1993. "Blackmail, Privacy, and Freedom of Contract." University of Pennsylvania Law Review 141:1817-1843.

Powell, Jonathan M. 2014. "Trading coups for civil war: The strategic logic of tolerating rebellion." African Security Review 23(4):329-338.

Prorok, Alyssa K. 2017. "The (in) compatibility of peace and justice? The International Criminal Court and civil conflict termination." International organization 71(2):213-243.

Przeworski, Adam. 1991. Democracy and the market: Political and economic reforms in Eastern Europe and Latin America. Cambridge University Press.

Rev, Istvan. 2005. Retroactive Justice: Prehistory of Post-Communism. Stanford University press.

Rolston, Bill. 2006. "Dealing with the past: Pro-state paramilitaries, truth and transition in Northern Ireland." Human Rights Quarterly pp. 652-675.

Schelling, Thomas. 1960. The Strategy of Conflict. Cambridge and London: Harvard University Press.

Schwarz, Michael and Konstantin Sonin. 2008. "A Theory of Brinkmanship, Conflicts, and Commitments." Journal of Law, Economics, and Organization 24(1):163-183. 
Shavell, Steven. 1993. "An Economic Analysis of Threats and Their Illegality: Blackmail, Extortion, and Robbery." University of Pennsylvania Law Review 141:1877-1903.

Shavell, Steven and Kathryn Spier. 2002. "Threats Without Binding Commitment." Topics in Economic Analysis and Policy 2:1024-1024.

Sikkink, Kathryn. 2011. The Justice Cascade: How Human Rights Prosecutions Are Changing World Politics (The Norton Series in World Politics). WW Norton \& Company.

Simmons, Beth A and Daniel J Hopkins. 2005. "The constraining power of international treaties: Theory and methods." American Political Science Review 99(4):623-631.

Snyder, Jack and Leslie Vinjamuri. 2004. "Trials and errors: Principle and pragmatism in strategies of international justice." International security 28(3):5-44.

Tyson, Scott A. 2016. "The agency problem underlying the use of repression.".

Urueña, René. 2017. "Prosecutorial Politics: The ICC's Influence in Colombian Peace Processes, 2003-2017." American Journal of International Law 111(1):104-125. 


\section{Appendix}

Formalities of the Baseline Game. The set of Players is $\{I, O, m, B\}$. The ideological type of the opposition player, $P=\{E, M\}$, is unknown to anyone but the $O$ himself; for others, $\operatorname{Pr}\left(x_{O}^{M}\right)=$ $\theta$. In addition, $O$ may be compromised: let $k \in K=\{0,1\}$ represent the presence or absence of kompromat. $B$ and $O$ know the value of $k$; for others, $\operatorname{Pr}(k=1)=\mu$.

Players have ideal points $x_{B}, x_{O}^{E}, x_{O}^{M}, x_{m}, x_{I}$ in $S$, the policy space, and we assume that $x_{m}=0$, $x_{B}<x_{O}^{E}<x_{O}^{L}<0<x_{I}$ and that $x_{I}>\left|x_{O}^{M}\right|$.

Players' strategies are defined as follows:

$S_{B}=\left\{R \subset S:\right.$ if $x_{O} \in R$ then B releases kompromat $\}$ is the blackmailer's strategy set;

$S_{I}=\{T, N\}$, where $T$ refers to a transparency regime and $N$ refers to a non-transparency regime, is the strategy set of the incumbent;

$S_{O}=\{P \times K \rightarrow S\}$ is the strategy set of the opposition challenger;

$S_{m}^{E}=\left\{\{T, N\} \times K \rightarrow\left\{x_{I}, x_{O}\right\}\right\}$ is the voters' strategy set at the elections stage;

$S_{m}^{R}=\{[0,1] \rightarrow\{$ Remove, Not Remove $\}$ is the voters' strategy set at the removal stage.

Preferences are Euclidean and given by $u_{i}(x)=-\left|x-x_{i}\right|$, where $i=I, M, B$. For $O$, the

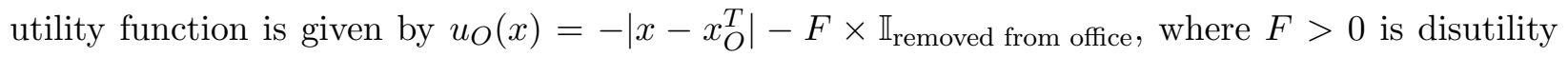
large enough so that the opposition leader prefers to depart from the ideal policy rather than be removed from office. In addition, voters $(m)$ suffer disutility of $\varepsilon>0$ if $k=0$ and the politician is removed from office, and disutility of $D>0$ if $k=1$ and the politician stays in office.

Proposition 1 describes the following perfect Bayesian equilibrium.

- $s_{I}^{*}=N, s_{m}^{E *}=\left(x_{O}, x_{I}\right), s_{B}^{*}=\mathbb{R} \backslash\left\{x_{O}^{E}\right\}$,

- $x_{O}^{*}=\left\{\begin{array}{l}x_{O}^{E} \text { if } k=1 \text { and } P=M, \\ x_{O}^{E} \text { if } P=E, \\ x_{O}^{M} \text { if } P=M \text { and } k=0,\end{array}\right.$

- $\operatorname{Pr}\left(k=1 \mid x_{O}^{M}\right)=0$,

- $\operatorname{Pr}\left(k=1 \mid x_{O} \notin\left\{x_{O}^{E}, x_{O}^{M}\right\}\right)=1$,

- $\operatorname{Pr}\left(k=1 \mid x_{O}^{E}\right)=\frac{\mu}{(1-\theta)+\mu \theta}$,

- $s_{m}^{R *}=$ Remove if $\operatorname{Pr}\left(k=1 \mid x_{O}^{*}\right)>\frac{D-\theta\left(x_{O}^{M}-x_{O}^{E}\right)}{D+\varepsilon}$. 


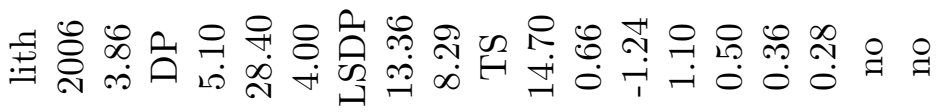

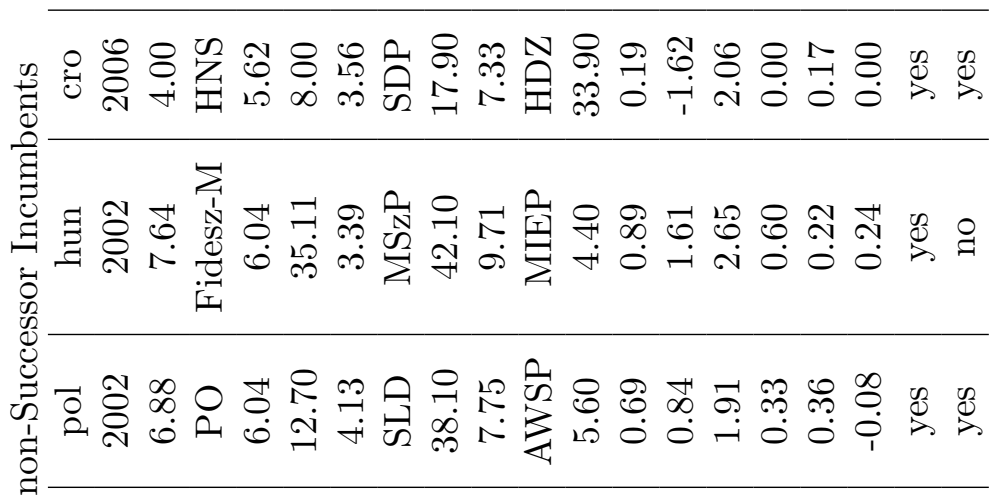

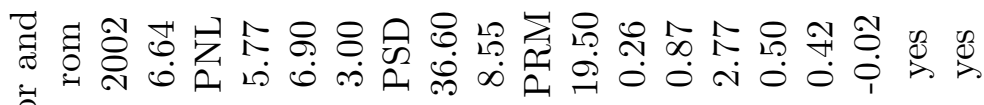

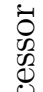

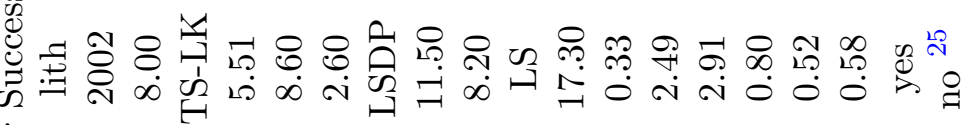

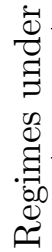

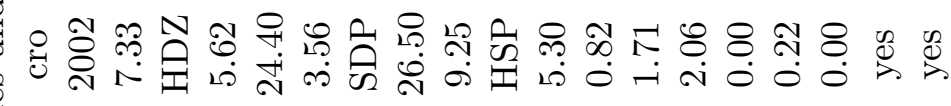

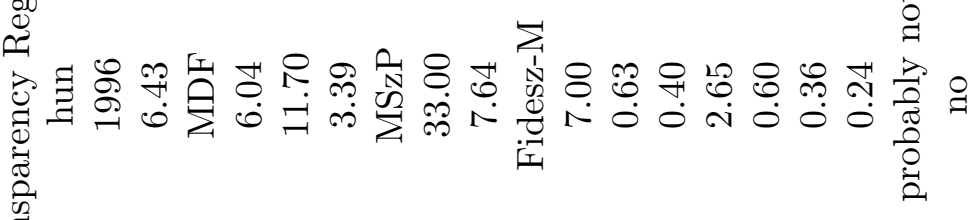

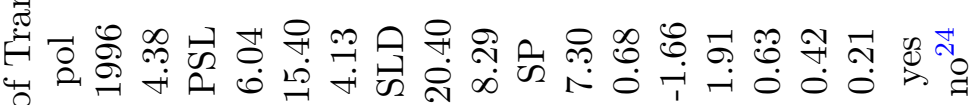

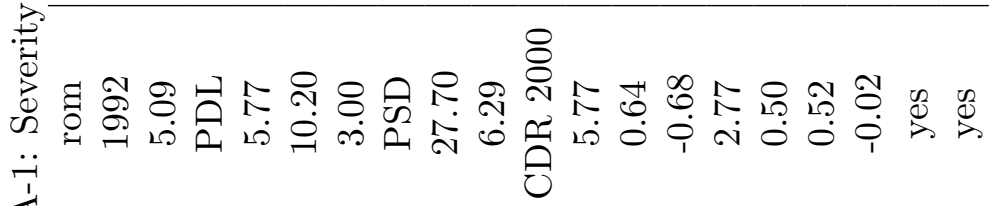
$\frac{0}{\frac{0}{\sigma}}$

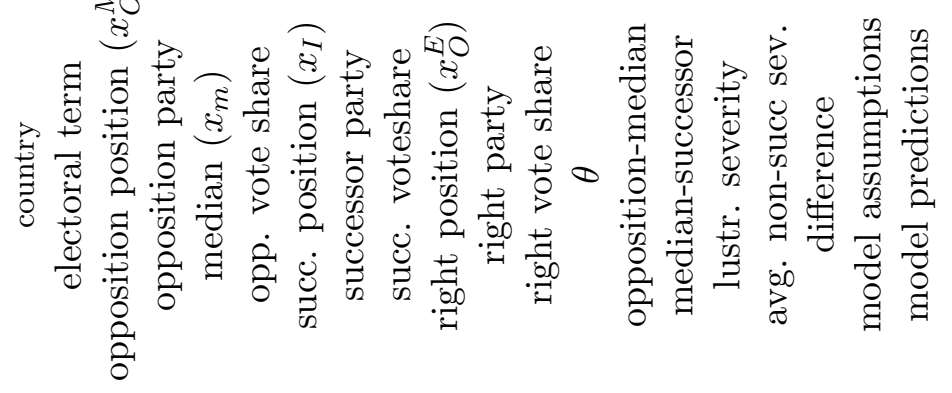




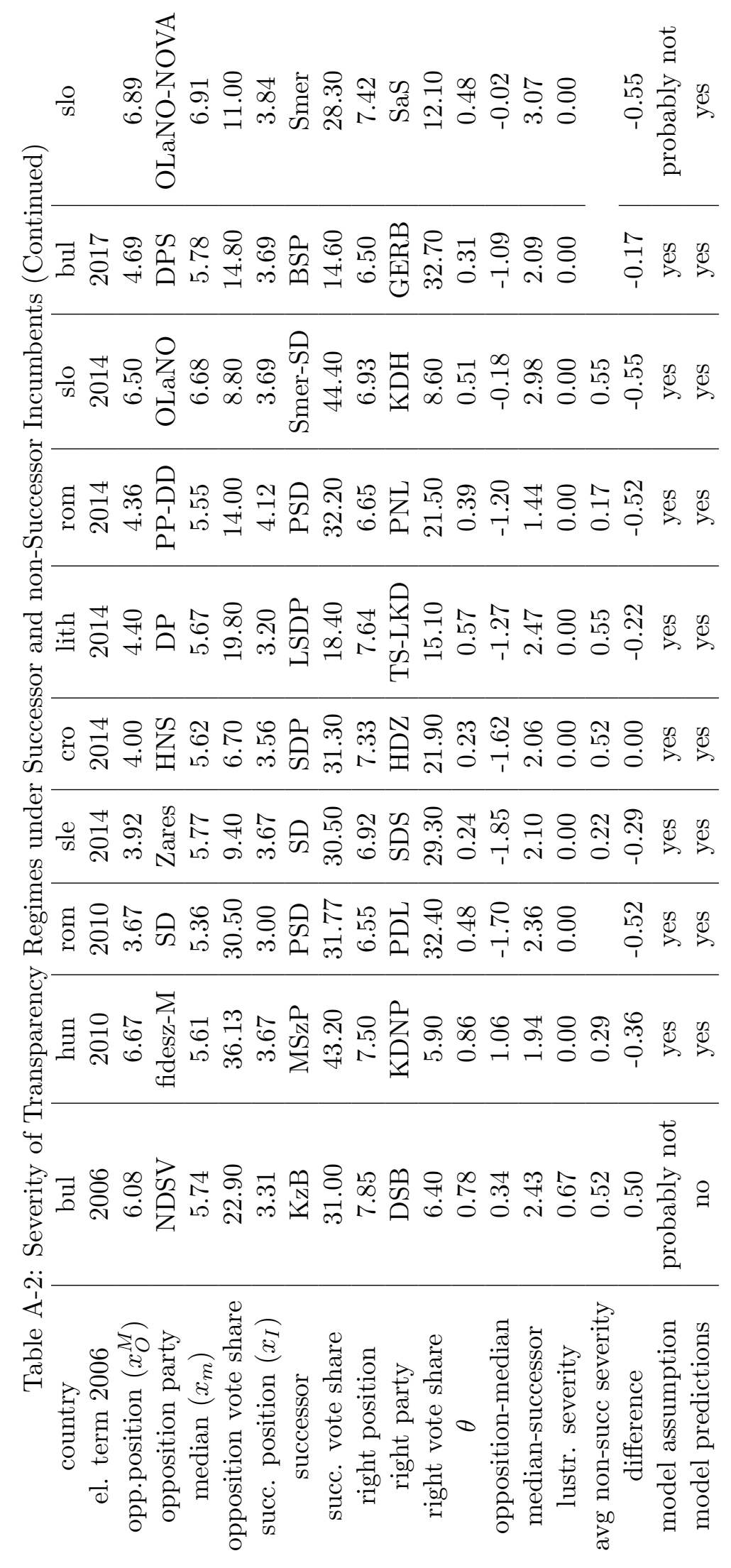


Qualitative Appendix All interviews cited in this paper were conducted by one of the authors in the 2003/2004 in Poland, Hungary and the Czech Republic. The research was funded by an NSF Dissertation Improvement grant and the Interview Protocol approved by the appropriate Institutional Review Board. Interviewees were informed about how there data obtained from them will be use and how their responses will be coded to preserve anonymity. The complete database with identifying information removed is available upon request from the authors. 